\title{
Current issues in medically assisted reproduction and genetics in Europe: research, clinical practice, ethics, legal issues and policy
}

\author{
European Society of Human Genetics and European Society of Human Reproduction and Embryology
}

Joyce C Harper ${ }^{\star, 1}$, Joep Geraedts ${ }^{2}$, Pascal Borry ${ }^{3}$, Martina C Cornel ${ }^{4}$, Wybo Dondorp ${ }^{5}$, Luca Gianaroli ${ }^{6}$, Gary Harton $^{7}$, Tanya Milachich ${ }^{8}$, Helena Kääriäinen ${ }^{9}$, Inge Liebaers ${ }^{10}$, Michael Morris ${ }^{11}$, Jorge Sequeiros ${ }^{12}$, Karen Sermon ${ }^{13}$, Françoise Shenfield ${ }^{14}$, Heather Skirton ${ }^{15}$, Sirpa Soini ${ }^{9}$, Claudia Spits ${ }^{13}$, Anna Veiga ${ }^{16}$, Joris Robert Vermeesch ${ }^{17}$, Stéphane Viville ${ }^{18}$, Guido de Wert ${ }^{5}$ and Milan Macek Jr ${ }^{19}$ on behalf of ESHG, ESHRE and EuroGentest2

In March 2005, a group of experts from the European Society of Human Genetics and European Society of Human Reproduction and Embryology met to discuss the interface between genetics and assisted reproductive technology (ART), and published an extended background paper, recommendations and two Editorials. Seven years later, in March 2012, a follow-up interdisciplinary workshop was held, involving representatives of both professional societies, including experts from the European Union Eurogentest2 Coordination Action Project. The main goal of this meeting was to discuss developments at the interface between clinical genetics and ARTs. As more genetic causes of reproductive failure are now recognised and an increasing number of patients undergo testing of their genome before conception, either in regular health care or in the context of direct-to-consumer testing, the need for genetic counselling and preimplantation genetic diagnosis (PGD) may increase. Preimplantation genetic screening (PGS) thus far does not have evidence from randomised clinical trials to substantiate that the technique is both effective and efficient. Whole-genome sequencing may create greater challenges both in the technological and interpretational domains, and requires further reflection about the ethics of genetic testing in ART and PGD/PGS. Diagnostic laboratories should be reporting their results according to internationally accepted accreditation standards (International Standards Organisation - ISO 15189). Further studies are needed in order to address issues related to the impact of ART on epigenetic reprogramming of the early embryo. The legal landscape regarding assisted reproduction is evolving but still remains very heterogeneous and often contradictory. The lack of legal harmonisation and uneven access to infertility treatment and PGD/PGS fosters considerable cross-border reproductive care in Europe and beyond. The aim of this paper is to complement previous publications and provide an update of selected topics that have evolved since 2005. European Journal of Human Genetics (2013) 21, S1-S21; doi:10.1038/ejhg.2013.219

In 2004, the Public and Professional Policy Committee ${ }^{1-4}$ of the European Society of Human Genetics $(\mathrm{ESHG})^{5}$ felt the need for professional recommendations on how to use assisted reproductive technologies (ARTs) safely and reliably from the genetic point of view, as well as issuing guidelines on acceptable goals of ART-based treatment and its prioritisation in European healthcare systems. It was thus decided to approach the European Society of Human Reproduction and Embryology (ESHRE) ${ }^{6}$ to undertake such work together. After several preparatory meetings of a working group, a joint ESHG/ESHRE meeting was held in Seville, 31 March to 1 April 2005 and a paper summarising the meeting was published, ${ }^{1}$ together with joint recommendations endorsed by the ESHG and ESHRE in both society journals ${ }^{3,7}$ and an Editorial. ${ }^{2}$

Seven years later, on 5-6 March 2012, an expert group of the ESHG, ESHRE and EuroGentest2 representatives met again in Brussels to assess the changes that had occurred in the field and to

${ }^{1}$ UCL Centre for PG\&D, Institute for Womens Health, University College London, London, UK; ${ }^{2}$ Faculty of Health, Medicine and Life Sciences, Department of Genetics and Cell Biology, Research Institute GROW, Maastricht University, Maastricht, The Netherlands; ${ }^{3}$ Department of Public Health and Primary Care, KU Leuven, Leuven, Belgium; ${ }^{4}$ Department of Clinical Genetics, EMGO Institute for Health and Care Research, VU University Medical Center, Amsterdam, The Netherlands; ${ }^{5}$ Faculty of Health, Medicine and Life Sciences, Department of Health, Ethics and Society, Research Institute GROW, Maastricht University, Maastricht, The Netherlands; ${ }^{6}$ Reproductive Medicine Unit, S.I.S.Me.R., Bologna, Italy; ${ }^{7}$ School of Biosciences, University of Kent, Canterbury, UK (formally Reprogenetics, Livingston, NJ, USA); ${ }^{8}$ SAGBAL Hospital 'Dr Shterev', MC 'Reproductive Health', Sofia, Bulgaria; ${ }^{9}$ National Institute for Health and Welfare (THL), Helsinki, Finland; ${ }^{10}$ Center for Medical Genetics, Vrije Universiteit Brussel, Brussels, Belgium; ${ }^{11}$ Department of Molecular Diagnostics, Synlab Lausanne, Lausanne, Switzerland; ${ }^{12}$ ICBAS-Instituto de Ciências Biomédicas Abel Salazar and Institute for Molecular and Cell Biology, University of Porto, Porto, Portugal; ${ }^{13}$ Department of Embryology and Genetics, Vrije Universiteit Brussel, Brussels, Belgium; ${ }^{14}$ Reproductive Medicine Unit, Institute for Women's Health, University College London, London, UK; ${ }^{15}$ Faculty of Health and Human Sciences, Education and Society, School of Nursing and Midwifery, Plymouth University, Plymouth, UK; ${ }^{16}$ Reproductive Medicine Service, Institut Universitari Quiron Dexeus, Barcelona, Spain; ${ }^{17}$ Centre for Human Genetics, KU Leuven, Leuven, Belgium; ${ }^{18}$ Institute of Genetics and Molecular and Cellular Biology (IGBMC), Centre National de Recherche Scientifique (CNRS) UMR 1704 , IIIkirch, France; ${ }^{19}$ Second Faculty of Medicine, Department of Biology and Medical Genetics, Charles University and Faculty Hospital Motol, Prague, Czech Republic

*Correspondence: Dr JC Harper, UCL Centre for PG\&D, Institute for Womens Health, University College London, 86-96 Chenies Mews, London WC1E 6HX, UK. Tel: + 44 07880 795 791; Fax: + 440207383 7429; E-mail: joyce.harper@ucl.ac.uk

Consensus Meeting: 'Update on the interface between ART and Genetics' Brussels, Belgium, 5-6 March 2012. 
update the common background document, wherever needed, with selected issues. The result of these deliberations and review of the literature until May 2013 are presented in this paper.

\section{METHODS}

Selected topics relating to current issues in ARTs and reproductive genetics were discussed by an expert panel, in order to reflect developments in the field, both from research and clinical perspectives.

\section{RESULTS}

Substantial advances have occurred in the field of ART, including greatly expanded knowledge of the genetic causes of male and female reproductive failure. The relationship between the epigenome and infertility is still under investigation. Currently, the analysis of potential epigenetic and transgenerational effects of ART is still impossible in the absence of sizeable second- and third-generation study cohorts. In preimplantation genetic diagnosis (PGD), there has been an increased move to blastocyst biopsy and the use of new technologies for diagnosis, such as array comparative genomic hybridisation $(\mathrm{aCGH})$.

A recent meta-analysis of preimplantation genetic screening (PGS) has shown that using fluorescent in situ hybridisation (FISH), PGS results in a significantly lower live-birth rate. ${ }^{8}$ A recently published pilot randomised clinical trial (RCT) using aCGH showed an increase in implantation and ongoing pregnancy rates following chromosome screening on day 5, but reported a low pregnancy rate in the control group. ${ }^{9}$ More RCTs using newer technologies (aCGH, single-nucleotide polymorphism (SNP) arrays and sequencing) are necessary to make a decision on the utility of such approaches.

According to the Organisation for Economic Cooperation and Development (OECD) Guidelines for Quality Assurance in Molecular Genetic Testing, ${ }^{10}$ both PGD and PGS should be reported by accredited laboratories (International Standards Organisation - ISO $15189)^{11}$ or equivalent accreditation schemes. ${ }^{12}$

An increasing spectrum of genetic tests are being offered directly to the consumer (DTC) ${ }^{13}$ or directly through a physician without proper medical advice and/or appropriate genetic counselling. ${ }^{14}$ Highthroughput genomic technologies currently comprising wholeexome sequencing (WES)/whole-genome sequencing (WGS) not only offer great potential in reproductive genetics ${ }^{15}$ but also pose substantial challenges regarding their clinical utility, interpretation of results, detection of variants of unknown clinical significance and incidental (or unsought for) findings, including a variety of ethical issues for the index case and their relatives. ${ }^{16,17}$ Many of the advances in the field are primarily driven by rapidly developing technologies, with the healthcare services being unable to adequately cope with testing outcomes in terms of counselling and proper medical follow-up.

There have been several studies examining the genetic effects of assisted reproduction, from population genetics and the birth defects-related perspectives. ${ }^{18-21}$ Further studies and/or metaanalyses of studies utilising different methodologies, and eventually transgenerational follow-up, need to be performed in order to address some initial concerns in larger representative cohorts. In this regard, regular updates from the ESHRE PGD Consortium will be of vital importance. $^{22}$

Although legal aspects related to medically assisted reproduction are continually being revised in Europe, substantial heterogeneity remains and fosters cross-border reproductive care (CBRC). ${ }^{23}$ There are anecdotal reports that the current difficult economic situation in
Europe, and beyond, is negatively influencing reimbursement of ART, ${ }^{24}$ including deterioration of equal access to fertility treatment, ${ }^{25}$ as well as to genetic testing, in general, and to PGD.

The use of stem cells is increasing our knowledge of early human development and opens new therapeutic avenues in the area of fertility preservation. ${ }^{26}$

The panel noted that ARTs and reproductive genetics are fastmoving fields, with many new techniques rapidly being brought into the clinic. However, in many instances, clinical utility, safety, efficacy, counselling and ethical/legal aspects of these developments need to be further analysed. Basic research needs to be undertaken, followed by clinical trials, efficacy and safety studies, before new clinical practices are brought into routine treatment. ${ }^{27,28}$ Follow-up of children born by new procedures should be mandatory.

\section{DISCUSSION OF SELECTED ISSUES}

\section{European directives}

Recent European Union (EU) directives have had a significant impact on ART. In particular, the EU Tissue and Cells Directive (EUTCD; currently under revision $)^{29}$ and the supplementing technical directives $2006 / 17 / \mathrm{EC}^{30}$ and $2006 / 86 / \mathrm{EC}^{31,32}$ have led to new safety and quality standards for clinical and laboratory procedures performed within in vitro fertilisation (IVF). Most European countries already transposed them into their respective national legislations, thus regulating procurement, testing, processing, storage, distribution and import/export of reproductive cells and tissues. Moreover, the EU Directive $98 / 79 / \mathrm{EC}^{33}$ on in vitro diagnostic medical devices, known as the 'IVD Directive' is also currently under revision and may have a significant effect on the field of genetic testing and its interface with ART.

\section{Cross-border reproductive care}

CBRC refers to the care of patients who cross borders in search for reproductive treatment in another country, mostly because of local constraints. It needs to be stressed that the derogatory colloquial term of 'reproductive' tourism is felt to be inappropriate. Indeed, few people elect a priori to seek treatment away from their support system, whether familial or through state funding, if available, as, in general, they may feel vulnerable, isolated, not be fluent in the local language or fear of stigmatisation on their return home. $^{34}$

The reasons for CBRC vary but are more commonly because of legal constraints, where at least some techniques are forbidden to all or particular population groups, such as single women or same-sex couples. Other reasons include access limitations at home, including availability of a given technique, long waiting lists or age limits (eg, no national health treatment is generally available in the United Kingdom for women over 40 years, whereas in France state refunds are available until the age of 43 years), seeking better quality or cheaper treatment abroad, as well as previous failure at home. There is no ethical objection per se to CBRC, as it enhances the patient's autonomy and it also fits the principle of free movement of patients and expertise within the EU. ${ }^{35}$ Other ethical issues pertain mostly to the possibility of coercion and abuse of gamete (especially oocyte) donors, even though in Europe the compensation for donation must not be disproportionate to the extent that it becomes payment, according to the EUTCD (see the section 'European directives').

In spite of high media exposure, there was little data concerning CBRC until the first international European study was published, ${ }^{23}$ 
analysing the demographics, motivations and reasons for crossing borders of patients travelling to six European countries. This study was based on 1230 CBRC cycles recorded in 1 month, leading to a yearly estimation of a minimum of 25000 cycles. It confirmed that one of the main reasons for CBRC were legal restrictions, based on prohibition of the technique per se, or its inaccessibility related to some patients' characteristics (such as age, sexual orientation or civil status). It also highlighted that people tend to travel to the nearest country where the required technique is available. Examples include Germans seeking oocyte donation in the Czech Republic or French lesbian couples requesting donor insemination in Belgium. Some aspects are more problematic than others, not least concerning national law evasion, although 'there may be good reasons for people to bypass the law by travelling abroad. ${ }^{35}$ A major ethical principle and political issue is fair access, ${ }^{25}$ which should ideally be realised in the home country.

Concerned about the joint professional responsibility of all stakeholders involved in ART, the CBRC ESHRE Task Force also published a Good Practice Guide (GPG) for CBRC, for the information of patients, and all collaborators involved, including gamete donors and surrogates. ${ }^{36}$ This guide is articulated around the following core principles: equity, quality and safety (the last two often conflated in the outcome of a singleton healthy birth), evidencebased care, patient involvement, redress counselling and psychological support, which should preferably be provided in a language in which the recipient is fluent. The safety question is essential to care and is covered at least practically in the EU by some specific aspects of the EUTCD, such as laboratory conditions, and gametes donor screening for viral illnesses as well as their 'compensation', where the term 'noncommercialisation' is mentioned as a 'protective' feature against exploitation. Indeed, the notion of compensation is at the ethical core of donation. If compensation becomes payment, appropriate consent may be undermined by enticement. Moreover, there may be pressure on vulnerable, low-income women, turning them into gamete vendors rather than donors. ${ }^{37}$ The avoidance of intermediate agencies ('brokerage'), which may lead to violations of GPG and, in the worst case, to abuse of women in low-resource countries is advisable. ${ }^{37}$ Last but not least, the welfare of the future child should be at the centre of safety and ethical concerns, taking care of promoting the 'decline in the number of multiple births', which 'can be regulated only with a reduction of the total number of embryos transferred. ${ }^{38}$

Joint responsibility is of course a complex moral and legal problem, especially when taking into account varied European legal frames. ${ }^{39}$ Information sharing across borders is essential, but increasing safety and good practice for all concerned in CBRC is currently mostly work in progress. For instance, the ESHRE GPG is now posted on the websites of many national societies and regulatory bodies within Europe, ${ }^{40}$ as well as the patients' organisation 'Fertility Europe. ${ }^{41}$

Finally, other challenges are also looming, as oocyte banking is becoming much more efficient owing to vitrification. ${ }^{42}$ This means that eggs have started crossing borders as well, perhaps enabling some patients to stay at home in their preferred environment, but making it more difficult to check the conditions of gamete donation for all concerned. ${ }^{43}$

\section{Genetic aspects of female infertility}

Besides taking a personal and familial history, a medical examination and the basic tests, such as hormone profiles, and medical examination of the female reproductive system, an increasing amount of genetic tests are being offered to females suffering from infertility.
Genetic testing of females with ovarian insufficiency and amenorrhea should consist of a chromosomal analysis and fragile X-mental retardation-1 gene (FMR1) 'expansion' CGG(n) testing. ${ }^{44}$ Other more specific tests looking for the blepharophimosis-ptosisepicanthus inversus syndrome caused by FOXL2 mutations, ${ }^{45}$ galactosemia (GLAT mutations), ${ }^{46}$ or less commonly $P O L G$ mutations ${ }^{47}$ associated with a mitochondrial disease should be performed if clinically indicated. Rarer causes of female infertility, such as those due to mutations in the follicle-stimulating hormone receptor or the luteinising hormone/choriongonadotropin receptor, should also be kept in mind and investigated whenever necessary. ${ }^{48,49}$ Other rare hereditary conditions, such as Kallmann syndrome (KS), ${ }^{50}$ androgen insensitivity ${ }^{51}$ and adrenal hyperplasia may be diagnosed as causes of female infertility. ${ }^{52}$ In cases of recurrent miscarriages (at least three times), ${ }^{53}$ and for examining balanced translocations and/or other structural anomalies, chromosome analysis should be performed. ${ }^{52}$ Inherited thrombophilia testing requires standardisation and further meta-analyses in order to substantiate its clinical utility. ${ }^{54}$

If a genetic cause of infertility is established, genetic counselling should be provided (see the section 'Counselling within the reproductive medicine and genetic contexts'). Depending on the type of genetic anomaly, various treatments may be offered, such as IVF, with or without PGD, gamete or embryo donation. Further family testing ('cascade screening') should be discussed. If an FMR1 (GGC) expansion is diagnosed in premature ovarian insufficiency, ${ }^{55}$ IVF with PGD may help the couple to conceive a child unaffected by the Fragile X syndrome (FXS) and further testing of family members of the female partner has to be used. For each genetic condition diagnosed, the appropriate therapeutics and counselling approach should be discussed. It is important to remember that PGD may be indicated whenever facing a genetic condition and infertility, and should be discussed in counselling, together with all other possible reproductive options. ${ }^{56,57}$

For the more common conditions observed in the infertile female, such as polycystic ovary syndrome, ${ }^{58}$ endometriosis ${ }^{59}$ and certain anomalies of the female reproductive system, no diagnostic genetic test is available, as these conditions are multifactorial.

In conclusion, a 'cascade' diagnostic evaluation of an infertile couple may allow a genetic diagnosis based on chromosomal abnormalities or an FMR1 expansion. Further evaluations may reveal other markedly rarer conditions. A multidisciplinary approach, including genetic counselling, is mandatory. New technologies, such as aCGH, WES or WGS, will probably enable identification of additional genes that have an important role in female reproductive failure. ${ }^{60}$

\section{Genetic aspects of male infertility}

Sperm counts (World Health Organisation criteria) ${ }^{61}$ are used for the assessment of male fertility. ${ }^{62} \mathrm{~A}$ sperm concentration of $<10 \times 10^{6}$ per $\mathrm{ml}$ or total sperm counts of $<10-15 \times 10^{6}$ is an indication threshold' for genetic testing. Currently, genetic testing is indicated primarily for the elucidation/confirmation of the underlying diagnosis and to assess the risk of infertility to the offspring (eg, when the index case is bearing a Y chromosome microdeletion following successful treatment by various forms of testicular sperm extraction, ${ }^{63}$ followed by intracytoplasmatic sperm injection (ICSI).

Recently, it has been estimated that roughly one quarter of patients with azoospermia (AZ) and severe oligozoospermia undergo genetic testing. ${ }^{64}$ The first examination of choice is karyotyping for common chromosomal aberrations, possibly followed by specific molecular 
tests. Interestingly, the lower the sperm count, the more chromosomal aberrations are found. ${ }^{65}$

Gonosomal aberrations are mainly represented by the Klinefelter syndrome $e^{66}$ (KFS: 47, XXY, including its various mosaic formulae) with a rather heterogeneous clinical presentation. This is one of the most common human chromosomal aneuploidies, with a prevalence of $\sim 1 / 650$ males. The majority of KFS cases are primarily diagnosed due to infertility; about $3 \%$ of infertile and $16 \%$ of azoospermic males have KFS. ${ }^{67}$ Currently, there is growing evidence that sperm extraction (see above) combined with ICSI can successfully treat some instances of KFS-related infertility ${ }^{68}$ and spermatogonial preservation is also being developed. ${ }^{69}$ Nonetheless, long-term studies are needed to evaluate the likelihood of a higher prevalence of chromosomal aberrations in their offspring.

In this context, it needs to be noted that the majority of men with chromosomal aberrations associated with infertility are apparently healthy, and do not have dysmorphic features or intellectual disability. Males with various forms of chromosomal translocations have a higher risk of repeated miscarriages or stillbirth in their offspring, as their balanced translocations may become unbalanced in their offspring. ${ }^{70}$

Pathogenic mutations or variants in the cystic fibrosis (CF) transmembrane receptor gene (CFTR) have been implicated in male infertility $^{71}$ and are associated with obstructive AZ due to congenital bilateral absence of the vas deferens (CBAVD) ${ }^{72}$ This association highlights the fact that patients with obstructive $A Z$ are candidates for CFTR genetic testing. ${ }^{73}$ Testing distinguishes obstructive AZ from AZ due to Y-chromosomal microdeletions. It is important to note that spermatogenesis in CBAVD is normal; thus, patients with CFTRrelated obstructive $\mathrm{AZ}$ can be treated by sperm extraction followed by ICSI, ${ }^{74}$ with their offspring having an increased risk of CF itself. Finally, association of congenital unilateral absence of vas deferens (usually linked to equilateral renal and urethral developmental anomalies) is not consistently associated with CFTR mutations. ${ }^{75}$

Various $\mathrm{Y}$ chromosome microdeletions are predominantly found in non-obstructive $\mathrm{AZ}$ or severe oligospermia. ${ }^{76}$ Molecular genetics diagnosis of such microdeletions is useful and feasible with a simple and robust test. ${ }^{77}$ Association of AZ factor (AZF) - AZF1a, AZF1b, $A Z F 1 b c$ and $A Z F 1 c$ - microdeletions with infertility is unambiguous. ${ }^{78}$ Although there are marked differences in the prevalence of these deletions between various studies (mainly due to variable inclusion/exclusion criteria in analysed cohorts), most (ie, >75\%) of these deletions comprise the AZF1c region. ${ }^{79}$ The association to sperm counts is proportional, in that AZ men have a higher prevalence of microdeletions than oligospermic patients. Testing of $A Z F 1$ microdeletions has a prognostic impact for sperm extraction, as no sperm can be retrieved in $A Z F 1 a$ and $A Z F 1 b$, whereas there is a fair chance that viable sperm could be retrieved in $A Z F 1 c^{80-82}$ In the latter instance, sperm can be found in the ejaculate, which is a preferable source for IVF/ICSI compared with various forms of surgical sperm extraction. Genetic counselling should be offered to the family following fertility treatment, as the underlying cause of male infertility will be transferred to successive generations. The $\mathrm{Y}$ chromosome $\mathrm{gr} / \mathrm{gr}$ deletions (NR3C1) are more likely to occur among infertile men with quantitative decrease of their sperm counts ${ }^{83}$ but their use in diagnostics is limited due to their low penetrance.

Alterations in the gonadotropin-releasing hormone $(\mathrm{GnRH})$ gene (GNRH1), implicated in disturbed neuronal migration, ${ }^{84}$ were found in congenital hypogonadotrophic hypogonadism $(\mathrm{HH}),{ }^{85}$ which presents as a variable syndrome characterised by low sex steroid and gonadotropin levels, due to impaired $\mathrm{GnRH}$ upstream stimulation, originating in the hypothalamus. The fully expressed syndrome with hyposmia/anosmia is described as KS (see the section 'Genetic aspects of female infertility'), with bulbus olfactorius agenesis as its main feature. However, the marked underlying genetic heterogeneity ${ }^{86}$ and variable expressivity and penetrance of such genetic factors are confounding factors for genetic diagnosis. Various mutations in the respective genes are found in half of the familial cases of $\mathrm{HH}$, but only exceptionally in sporadic forms. Moreover, substantial clinical heterogeneity of $\mathrm{HH}$ makes genotype-phenotype correlations difficult. Thus far, diagnostic utilisation of specific $\mathrm{HH}-$ related gene mutation panels is limited and more research is needed. ${ }^{87}$ Similar conclusions are applicable to the diagnostic testing of the androgen receptor $(A R)$ gene. ${ }^{88}$ Mutations in this gene are found in $\sim 1 \%$ of patients with $\mathrm{AZ}$ or severe oligozoospermia. It should be noted that examination of the entire $A R$ gene is needed. However, detection of variants of unclear clinical significance limits the diagnostic utility of sequencing.

Recently, reviews of SNP variants ${ }^{89}$ and genome-wide association studies $^{90}$ have provided evidence that there are multiple SNPs significantly associated with decreased sperm counts, ${ }^{91}$ but their functional consequence still needs to be clarified. In rare cases of male infertility ( $<0.1 \%$ of all instances), molecular alterations in SPATA16, PICK1 and DPY19L2 have been associated with globozoospermia, ${ }^{92}$ as well as in AURKC in the sperm macrocephaly syndrome. ${ }^{93}$ The role of alterations of the mitochondrial $\mathrm{DNA}^{94}$ in male infertility and in association with ICSI treatment requires further research.

Because of the advances in the use of aCGH, copy number variants $(\mathrm{CNVs})^{95}$ have been studied at the level of the entire genome or just of the Y chromosome. However, in the absence of known biological functions of affected genes, it is difficult to assess their clinical significance and more studies are required. Additional lines of research are necessary in order to assess the role of obesity, ${ }^{96}$ environmental pollution with endocrine disruptors ${ }^{97}$ and controversial impact of cell phone radiation ${ }^{98}$ on male fertility, to name just a few prominent examples recently discussed in the medical literature.

It is possible that the majority of idiopathic male and female infertility could be elucidated by WES/WGS analyses, ${ }^{99}$ but clinical interpretation of obtained genomic data remains challenging. ${ }^{100}$ This problem is not only due to the detection of variants of unknown clinical significance, but is also related to the 'clinical continuum' with which such variants ought to be associated with.

Finally, genomic complexity together with proteome analysis adds a further, unexplored, level of complexity. ${ }^{101}$ Therefore, utilisation and combination of the various 'omics' technologies within the systems biology framework, together with robust bioinformatics, may bring the necessary breakthroughs in the study of genetic causes of human infertility. Thus, at the moment there is no routine 'diagnostic' indication for WES-/WGS-based approaches in male or female infertility, that is, beyond the research setting. ${ }^{102}$

\section{Counselling within the reproductive medicine and genetics contexts}

Genetic causes of reproductive failure are now better understood and more thoroughly investigated, whereas counselling of infertile couples (both reproductive and genetic) has markedly improved. ${ }^{2}$ Appropriate counselling based on the medical, family and reproductive history should be offered and genetic testing should be implemented when indicated. If a genetic cause is suspected, the couple should be referred to a medical/clinical geneticist, according to 
provision in various countries. ${ }^{1}$ There is still, however, the need to define clearly how far to investigate the causes of infertility and to harmonise the criteria for involving specific professionals, from reproductive counselling (by obstetricians, gynaecologists and ART specialists) to genetic counselling performed by clinical geneticists and genetic counsellors/nurses.

The extent of information provided in counselling should be adapted to the particular reason for ART and PGD, as well as to the needs of each couple. The content should include risks for the couple (eg, ovarian hyperstimulation syndrome, waiting time, psychosocial stress and limited pregnancy success rate), as well as to the embryo, fetus and child to be born. This includes the low risk for congenital malformations or genetic disease, decreased birth weight and survival, multiple pregnancy and associated problems, and laterlife disorders, as well as the current scientific limitations and uncertainties that still surround these techniques, and the immediate, medium and long-term outcomes. ${ }^{103,104}$

Couples should be provided with evidence-based information on the techniques and their implications, as well as on the performance of an infertility clinic. Standardised information should be presented, including clinic success rate per oocyte retrieval, delivery rate per oocyte retrieval and the percentage of singletons born. Such benchmarking practice may have improved but is still not applied in many centres and countries. Local professional guidelines or other forms of regulation (eg, statutory) are needed. Autonomy of couples has to be respected, although professionals have a duty to convey the wider perspective, primarily considering the future child's interest. ${ }^{1,105}$

The possible use of genetic techniques in ART treatment is discussed with the patients in the course of reproductive counselling ${ }^{56,57}$ as performed by the professionals working in ART settings. Some may wish to understand these issues more thoroughly and, for instance, ask about possible consequences related to the risk of imprinting of genes predisposing to the common diseases of adult age. As the oldest 'IVF children' are at present only about 35 years of age, whereas the oldest ICSI child is 20 years old, ${ }^{106}$ this question cannot be answered. Such questions may sometimes require a discussion with a specialised professional, that is, clinical geneticist.

Genetic counselling is a communication process that involves discussing the problems associated with a genetic condition. ${ }^{107,108}$ A typical genetic counselling consultation encompasses the familial, scientific, psychological and social aspects of being at risk or being affected. Key concepts in genetic counselling practice are relevant information exchange, the presentation of choices relevant to the patient and exploration of patient values and beliefs. In traditional genetic counselling (of fertile prospective parents), a non-directive approach is considered to be of paramount importance. In view of the responsibility of the professional involved in medically assisted reproduction to take account of the welfare of the child, however, a more directive approach may occasionally be justified in this particular context (see the section 'Ethical issues related to assisted reproduction and reproductive genetics'). Although genetic counselling may be provided by any appropriately trained and skilled health practitioner who has achieved the relevant core competences, ${ }^{109}$ the term 'genetic counsellor' should apply only to those who are specifically educated for this role. ${ }^{110}$

In spite of the fact that ART treatment is almost always associated with issues requiring genetic screening/testing, genetic counselling may not always be needed. The treatment itself may involve the use of genetic screening methods, such as aneuploidy screening, as a part of PGS. Furthermore, according to present knowledge, ART appears to be associated with a small, but not negligible, risk for genetic consequences in the form of epigenetic changes leading to congenital disorders. ${ }^{111}$ The cause of infertility may be genetic, which may have further implications related to the health of the offspring if the infertile parent's own germ cells are used. Finally, the very reason for ART treatment may be the risk of a genetic condition in the family and the desire for PGD. In these cases, the need for genetic counselling is explained below and some examples are given.

Where genetic risks are related to the cause of infertility, genetic counselling is always required. Usually, the aetiology of the infertility is diagnosed in the infertility clinic. If the cause is genetic and there are possible consequences for the offspring, the couple should be referred for genetic counselling. The cause itself is explained and the implications for the person's close relatives (eg, siblings) are discussed as well. The couple may feel that they need support in informing the relatives, if needed: this can usually be provided by genetics health professionals. The couple may be reluctant to discuss these issues during current treatment, in which case the discussion can be planned for later. Situations where genetic counselling should always be extended to the family, at least to the siblings of the index case, include chromosomal translocations and some conditions leading to female infertility (eg, ovarian dysfunction in FMR1 premutation carriers) or male infertility (especially in mutations/variants of CFTR leading to CBAVD; see above), where in particular first-degree relatives are at risk of having the same problem and/or their disease may have unexpected serious consequences for their offspring. These issues are more complicated in the case of using genome-wide diagnostic assays such as the currently used aCGH. ${ }^{112}$

For couples, the crucial question usually is the possible healthrelated risk to the children to be born. Here the 'risk tolerance' of the couples may be very different. For instance, in case of CBAVD, some couples may wish to have the treatment without further investigation of the spouse, because they do not want having their pregnancy more 'medicalised' despite the risk of having a child with CF. Similarly, in cases of Y chromosome microdeletions some couples may consider the risk of infertility for the male offspring a concerning issue, whereas others are willing to accept this consequence in a male who could later benefit from ICSI. In any case, an individualised approach to counselling is of paramount importance, without disregarding the professionals' own responsibility to take account of the welfare of children conceived by ART (see the section 'Equal access, prevention of infertility, public funding of assisted reproduction').

A current example of one of the most complicated situations in genetic counselling of infertile couples is related to CBAVD. ${ }^{113}$ Usually, these men have two CFTR mutations: ${ }^{113}$ one CF-causing (hence serious) mutation, which in homozygosity or a compound heterozygous status would lead to the classical form of CF, and one 'mild' mutation or variant in trans. This combination typically leads to CBAVD with no other features of CF which determines the phenotype. If ICSI is performed with sperm of such an individual, the offspring will inherit either one of those mutations. If the spouse also carries a CF-causing mutation, where the carrier frequency is of the order of 1/25-30 in most European-derived populations, the offspring has a $1 / 4$ risk of inheriting $C F$, while male offspring will have an additional $1 / 4$ chance of inheriting CBAVD. If neither of these situations is acceptable to the couple, as many as $25-50 \%$ of the embryos may turn out to be 'affected'.

Another problem is that genetic testing for CFTR mutations in the spouse is complicated. Optimally, when predefined population specific testing panels are used (eg, using commercial diagnostic assays) she may be found to carry a mutation with defined clinical consequence. ${ }^{114}$ However, if sequencing is carried out she may be 
found to have a mutation (eg, missense or splicing) and/or variant of unclear clinical significance. Furthermore, even if no mutations are found in the CFTR gene, there may be rarer CF-causing mutations, ${ }^{113}$ which are not present within used assays or the pathogenic variant may reside in the intron. Importantly, most CFTR diagnostic assays had been optimised for Western European populations and thus have decreasing mutation detection rates in Southern- and Eastern Europe. Examination of intra-CFTR rearrangements adds to the complexity of diagnostic testing in CF. All this may be difficult for the couple to comprehend and it markedly increases the burden of their ART treatment and makes genetic counselling more challenging.

Some couples opt for ART treatment, because the fetus is at high risk for a genetic condition and they wish to avoid termination of pregnancy (TOP). These couples may have undergone genetic counselling previously, at the time of the diagnosis of the disease in their family, and may be aware of the disease in the family and their risk of having an affected child. If such a couple is considering PGD, genetic specialists (medical geneticists and genetic counsellors/nurses) ideally should meet the couple again before the possible treatment for further counselling. PGD is only one of several options available to couples that wish to avoid having an affected child; others include having no children, having no genetic testing, having prenatal diagnosis (PND) potentially associated with TOP, using donor ova or sperm, or adoption. There is, at present, a paucity of research into the experiences of couples who have used PGD. However, a recent Australian study reported, in 14 women who had used PGD, that it had enabled them to feel more empowered with regard to their reproductive lives. ${ }^{115}$

Decisions regarding the use of PGD are based on cognitive appraisals, emotional responses and moral judgments. For instance, when couples have the task of dealing with risk-based information, conflicting emotions and their own moral perspectives have a major influence on their decision about accepting or declining PGD; therefore, quality of care for couples requires counselling that incorporates these three aspects of their decision. ${ }^{116}$ It is important that the option of PGD is mentioned during genetic counselling in all relevant cases, as the couple's attitude towards using this technique cannot be assumed. Patient-oriented research has indicated that couples wish to have the option presented to them by a health professional. Couples who have experienced PND and TOP previously may be more likely to consider PGD, as may those who already have an affected child. ${ }^{115}$ Those who wish to avoid TOP may also see PGD as a viable option. On the other hand, there are also some couples who wish for a pregnancy that is 'natural', if possible, and who would therefore decline the use of this technique. PGD should be the method of choice to avoid transmission of the condition, where couples with a genetic risk need IVF because of infertility. Finally, costs of PGD, eventual necessity for successive confirmatory PND (due to the possibility of misdiagnosis), together with the necessity to undergo IVF, constitute major limiting factors for the fertile couple.

Genetic counselling before PGD is complex. ${ }^{117}$ This may be due to the combination of significant family and genetic history and complicated reproductive history, often involving loss of previous affected children or multiple TOP. Adequate information to make a decision must be provided, and some couples who have used PGD reported wanting more information than they were given. ${ }^{115}$ The experience of the condition in the family needs to be explored and acknowledged, as this may have a powerful impact on the decision. It is also important to acknowledge that there may be no 'right' or wrong' decisions, especially in the context of decisional conflict associated with the choice to have PGD. ${ }^{116}$
Conflict may also exist between the partners, especially if they bring different moral perspectives. The role of the genetic counsellor is to support the couple in coming to a decision that takes into account their values and beliefs. Perhaps uniquely among the health professionals involved, the genetic counsellor is also required to address wider family issues, to identify others in the family who might be at risk, to discuss how this information may be disclosed and, if appropriate, to arrange to offer cascade testing to other family members (see the section 'Ethical issues related to assisted reproduction and reproductive genetics').

The recommendations on provision of PGD indicate that genetic counselling should be provided by trained professionals. In some countries (eg, in Canada), this is already being provided by genetic counsellors, ${ }^{118}$ and it would appear that these professionals are appropriately equipped to provide this service. In Europe, there has been a variation in the development of the genetic counselling profession in each country. Recently, coordinated European initiatives $^{110}$ are facilitating common standards of genetic counselling practice and education. Moreover, establishment of the European Board of Medical Genetics within ESHG, which aims to ensure the highest levels of competence of physicians, scientists and counsellors working in medical genetics across Europe and to enhance their mobility by the development of portable EU-wide qualifications, will ensure harmonisation of counselling related to PGD.

\section{PGD and PGS}

PGD is a diagnostic test used to select genetically or chromosomally normal embryos for patients at high risk of transmitting a specific abnormality to their children. Even though these patients will often be fertile, they have to undergo IVF/ICSI to generate embryos in vitro, which will be biopsied, and these cells will subsequently undergo genetic testing. The disease or chromosome abnormality needs to be previously identified, so that specific (targeted) genetic testing could be performed. Embryos that are free from the disease tested will be transferred into the uterus.

PGS is an adjunct to IVF and is used to aid embryo selection for certain groups of patients, including those with advanced maternal age, repeated IVF failure, repeated miscarriage with normal karyotypes in the parents and severe male factor.

For both PGD and PGS, there are three stages during which cells can be removed for genetic testing. ${ }^{119}$ Polar body (PB) biopsy involves the removal of the first and/or second $\mathrm{PB}$, either simultaneously at the zygote stage or sequentially at the oocyte and then zygote stage. The major limitations of PB biopsy are that only maternal chromosomes are analysed. Some centres only examine the first PB, but this will not give a complete picture, as errors may also occur during meiosis II. PB biopsy is the most time consuming of all biopsy techniques, as all mature oocytes should be biopsied, some of which will not proceed to fertilisation or cleavage. PB biopsy renders the largest amount of samples to be examined compared with other biopsy techniques, especially if both $\mathrm{PB}$ are examined. ${ }^{120}$ This technique has mainly been developed in some countries (eg, Germany) with legal constraints for embryo selection.

To date, the most commonly used biopsy technique has been cleavage-stage biopsy, which is performed on day 3 of development, when the embryo is at the seven- to eight-cell stage. ${ }^{22,121}$ A hole is drilled in the zona pellucida and usually only one blastomere is aspirated. This technique allows the analysis of the embryonic genome (specific genes or chromosomes), but is complicated by the high levels of chromosomal mosaicism that occurs at this stage of preimplantation development. This is especially an issue for 
aneuploidy screening, as in 50\% of cases or more human preimplantation embryos exhibit at least two different cell lines. Therefore, the biopsied cell might not be a representative of the remaining embryo.

Blastocyst biopsy is being increasingly used. ${ }^{122,123}$ A hole is made in the zona pellucida, either on day 3 or day 5 , and the trophectoderm is allowed to herniate through the hole. Around five trophectoderm cells can be removed and used for the genetic analysis. Blastocysts exhibit less mosaicism but only around half of the embryos will reach the blastocyst stage, whereas in some patients blastocysts do not develop.

Freezing biopsied embryos has recently become very successful with the increasing use of vitrification. ${ }^{124}$ In some cases, all the biopsied embryos are vitrified, leaving more time for the genetic testing to be performed and also allowing samples to be sent to expert PGD centres for analysis.

Historically, two main techniques have been used for the genetic analysis in PGD: ${ }^{125}$ a PCR-based test for single-gene defects ${ }^{126}$ and FISH to examine chromosomes (for PGD of translocations and PGS). ${ }^{127}$ More recently, arrays have replaced FISH to examine chromosomes. ${ }^{128}$ Methods used in genetic testing in PGD/PGS have to be both robust and sensitive in order to be able to obtain a reliable result from a single or few cells. DNA contamination have to be taken into careful consideration. ${ }^{129}$

PCR-based techniques have developed over the last 20 years in order to allow a growing spectrum of diseases to be diagnosed at the single-cell level. Sensitivity has increased by using fluorescent primers and mini-sequencing or real-time PCR in mutation detection often combined with the analysis of linked DNA markers. PCR protocols have to take into account amplification failure, contamination and allele dropout, which is an extreme form of preferential amplification of a respective allele. ${ }^{126}$

Preimplantation genetic haplotyping is a clinical method of PGD, which involves whole-genome amplification (WGA) of the biopsied material and analysis of multiple microsatellite markers linked or optimally flanking the mutation site, in order to provide a more practical, yet accurate (due to a low risk of recombination), indirect approach to mutation analysis. ${ }^{130}$

FISH analysis of chromosomes in PGD/PGS has limited diagnostic accuracy and is now rarely used. ${ }^{127}$ FISH has been replaced by aCGH, which allows all chromosomes to be examined. ${ }^{125}$ In aCGH, the biopsied samples first undergo WGA, and the test and control samples are fluorescently labelled. Both samples are hybridised onto an array chip that may contain bacterial artificial chromosome, P1-derived artificial chromosome or yeast artificial chromosome clones, and results are simple to read, showing the copy number of chromosomes. ${ }^{131-134}$

SNP arrays can be used for single-gene disorders by linkage analysis, as well as for aneuploidy screening. ${ }^{135-137}$ However, the couple, and sometimes even their parents, have to be tested to obtain their haplotype in order to establish the linkage phase. The amount of information obtained is immense and it can also potentially detect predispositions to common diseases, physical characteristics and lateonset disorders. Its current limitation has been due to the increasing discovery of multiple CNVs of unknown clinical significance, which complicate counselling and often leave patients with unanswered questions. In this regard, detected CNVs should be added to international databases, such as DECIPHER, ${ }^{138}$ to enable assessment of their pathogenic potential through compilation of independent data on their clinical association.

PGD has several limitations when performed in fertile couples, as it is time consuming, stressful and, so far, rather costly if not covered by health insurance and/or health care systems. Occasionally, patients will only produce affected embryos; hence, there will be no available embryos to be transferred.

The main advantage of PGD is that it provides improved reproductive choice to the couple, thereby overcoming the possibly difficult decisions related to selective TOP. Couples should be made aware of the fact that embryo selection has to be performed based on the exclusion of selected genetic traits, whereas other traits are not accounted for. Because of the complex nature of PGD, there have been cases of misdiagnosis, some of which are caused by technical errors, whereas others are due to biological issues, such as mosaicism. ${ }^{129}$ It is therefore advisable that couples should be informed about the possibility to verify PGS/PGD results by standard PND or, more recently, by non-invasive prenatal testing (NIPT)/non-invasive prenatal diagnosis (NIPD) techniques within the early phase of pregnancy. ${ }^{139}$ The advantage of the latter technique is that it obviates the need to invasively sample fetal material by chorionic villus sampling or amniocentesis. ${ }^{140}$

The use of oligo-/SNP arrays and WES/WGS analyses will allow a substantial increase in the amount of genetic information that will become available from each embryo. In this context, it also needs to be noted that interpretation challenges will increase with highthroughput genomic techniques, as will the chance for the detection of incidental findings. ${ }^{141}$ These rapid technological developments will necessitate development of novel guidelines, interpretation algorithms and ethical frameworks (see the section 'Ethical issues related to assisted reproduction and reproductive genetics'). NIPT using cell-free fetal DNA and cell-free fetal RNA will improve the possibility to verify the PGD result in case of pregnancy and may possibly alter the demand for PGD/PGS in the future. ${ }^{142}$

PGS has increasingly been used in the past decade. Mastenbroek et $a l^{8}$ conducted a meta-analysis on the effect of PGS on the live-birth rate per patient. RCTs comparing IVF with and without PGS were included. FISH analysis was used in all trials and cleavage-stage biopsy was used in all but one trial. PGS significantly lowered live-birth rate after IVF for women of advanced maternal age (risk difference: -0.08 ; $95 \%$ CI: -0.13 to -0.03 ). For a live-birth rate of $26 \%$ after IVF without PGS, the rate was between 13 and 23\% using PGS. Trials where PGS was offered to women with a good prognosis and to women with repeated implantation failure suggested similar outcomes. The possible explanations for this observation are that the biopsied blastomere is not a true representation of the embryo at the eight-cell stage due to mosaicism, the biopsy procedure might cause harm and negative influences on the developmental potential of the biopsied embryo or FISH analysis did not allow examination of all chromosomes. ${ }^{143-145}$ To eliminate the problem of mosaicism at the blastomere stage, two approaches are possible: PB biopsy and trophectoderm biopsy. ESHRE conducted a proof-of-principle study to validate the use of aCGH for aneuploidy screening ${ }^{146}$ and has initiated a multicentre PB RCT using aCGH for advanced maternal age (ongoing at the time of publication).

Recent studies have suggested that biopsy of several trophectoderm cells from the blastocysts, followed by aCGH, might represent an optimal strategy for aneuploidy screening. The main question concerns the rate of mosaicism at the blastocyst stage and to what extent this might cause misdiagnoses. In a recent study, $42.3 \%$ of blastocysts were uniformly euploid, 30\% were uniformly aneuploid and $32.4 \%$ were mosaic. Of the mosaic embryos, $15.4 \%$ were found to be composed of a mixture of different cell lines, whereas $17 \%$ contained both normal and aneuploid cells. ${ }^{131}$ In the first prospective RCT directly measuring the predictive value of PGS, the clinical error rate was very low (4\%), whereas implantation and 
delivery rates of euploid embryos were increased relative to the entire cohort of transferred embryos. ${ }^{147}$ Another group of authors ${ }^{9}$ conducted a pilot RCT using blastocyst biopsy and aCGH-based PGS in a small group of young, good prognosis, patients. The authors demonstrated increased ongoing pregnancy and implantation rates as compared with a control group, but the control group showed a lower-than-expected pregnancy rate. This study included elective single embryo transfer in both arms. At this stage, it is too early to conclude whether a 24-chromosome screening is of value. Furthermore, it has to be shown which biopsy stage gives a better result: $\mathrm{PB}$ or trophectoderm.

The ESHRE PGD Consortium has analysed over 35000 cycles of PGD/PGS since 1997. ${ }^{22,121}$ The PGD Consortium has reported an increase in the quantity of $\mathrm{PB}$ and blastocyst biopsy, in the list of diseases diagnosed, and how the technology for diagnosis has evolved. The PGD Consortium has several working groups that are looking at follow-up of untransferred embryos, how the data is collected, how arrays are used, implementation of accreditation, and introduction of molecular methods and the outcomes of pregnancy. ${ }^{148}$

The Consortium has recently produced guidelines in four individual documents that can be read and considered together. Alternatively, each one of them could also be used individually. The four topics covered include the organisation of a PGD/PGS centre, amplification-based PGD, FISH-based PGD and embryology, as it relates to PGD and PGS. ${ }^{119,126,127,149}$ The Consortium have also produced a guide to PGD laboratory accreditation (Harper et al ${ }^{150}$; see the section 'Accreditation of laboratories in the field of reproductive genetics').

PGD should always be part of the information about reproductive options (together with PND, NIPT/NIPD, ${ }^{151}$ adoption and all other options) in preconception genetic counselling to couples and relatives from families with hereditary diseases. This includes information about the whole process, including the burden, invasiveness, limited success rate, cost and unknown risks for all those involved. The pros and cons of PGD must be properly balanced by honest information provision. Pre- and post-test genetic counselling should be performed in an adequate setting. Referral to a specialised psychologist should be made whenever needed. ${ }^{1}$

\section{Genomic variation in early human development and related diagnostic techniques}

It is by now well established that chromosomal abnormalities are inherent to human embryos. FISH analysis on human embryos detected a large incidence of abnormal blastomeres in normally developing, good quality, cleavage-stage embryos from IVF patients. ${ }^{152-154}$ A similar proportion of aneuploidy has been detected in embryos derived from normal fertile couples. ${ }^{155-157}$ Meta-analyses reviewing 36 studies, in which all blastomeres of cleavage-stage embryos have been analysed by at least 8 FISH probes, show that only $22 \%$ of embryos are euploid, ${ }^{158}$ with an increase up to $45 \%$ in blastocysts. ${ }^{131}$ Considering the mitotic error rate during the cleavage stage, analysis of single blastomeres will not provide insight in the genomic constitution of the other cells, nor in the developmental potential of the embryo. ${ }^{159,160}$

Aneuploid numbers of locus-specific FISH probe signals were in general interpreted as whole-chromosome imbalances, thereby neglecting the possibility of structural chromosomal aberrations. It was with the development of metaphase aCGH that the extent of whole-chromosome imbalances could be probed genome wide. For the first time also, segmental chromosome imbalances were reported in $\sim 7$ to $32 \%$ of embryos. ${ }^{161-164}$ aCGH has increased the resolution for single-cell analysis, revealing an even higher incidence of segmental rearrangements. ${ }^{135,159}$ As this high incidence was only observed in a limited series of studies, more investigations are warranted and technological advances are needed to (1) identify its true incidence, (2) associate the type and incidence with the referral reasons and (3) identify the origins of those imbalances.

Currently, two novel technologies are likely to further change our approach and ethical view towards genetic testing of embryos. First, the gradual introduction of WES/WGS testing into diagnostic practice will enable selection against embryos that will be affected by 'Mendelian' (or rare) disorders, but will indirectly result in a genome-wide view of the future of the developing embryo. ${ }^{136,165}$ Second, single-cell WES/WGS sequencing of individual blastomeres (or similarly sequencing small numbers of blastocyst cells) will provide the most in-depth view of the human genome at early stages of human development. ${ }^{166,167}$ It is important to assess the evolutionary, medical, ethical and legal consequences of these novel technologies in both clinical and community genetics and assisted human reproduction ${ }^{168-170}$ (see sections 'Ethical issues related to assisted reproduction and reproductive genetics' and 'Legal issues related to assisted reproduction and reproductive diagnostics').

\section{Accreditation of laboratories in the field of reproductive genetics}

The primary function of clinical genetic testing laboratories is to produce accurate and timely test results. However, data from genetics external quality assessment (EQA) schemes for many disorders reveal serious errors leading to misdiagnosis, typically concerning $1-5 \%$ of results for EQA samples. Errors of essentially all types are observed: misidentification of samples, false-positive and false-negative genotyping errors, misclassified mutations and serious errors of interpretation or of genetic nomenclature. ${ }^{171-175}$

The effects of an error in a genetic test can be significantly greater than that in other fields of laboratory medicine. Specific tests of the germline genome are typically performed once in a lifetime, and the results concern not only the tested individual but also untested relatives and offspring. Consequently, a genetic testing error can become fixed in the medical record of the patient and of other family members.

Proactive quality assurance (QA) should be implemented to meet the expectations of the consumers for reliable services. Quality standards need to be defined at the international, European and/or national level, both for laboratory procedures and other elements of ART, including counselling in the area of reproductive medicine and reproductive genetics. ${ }^{103}$

QA in genetic testing laboratories has many components, both technical and organisational. Licensing refers to the permission or permit from a governmental agency to operate a laboratory. Details vary between legislations but it does not typically involve evaluation of quality management and technical competence. Certification, typically according to ISO $9001,{ }^{176}$ attests compliance to a quality management system, but is not required to address technical competence, which severely limits its value in laboratories. Accreditation is a procedure by which an authoritative national body gives formal recognition that a laboratory is competent to carry out specific tasks. It involves expert audit of technical competence and quality management. The most appropriate accreditation standard for medical diagnostic laboratories is ISO $15189 .{ }^{11}$ Accreditation to this (or an equivalent) is considered as the single, most effective route to comprehensive laboratory QA as stipulated by the OECD 'Guidelines for Quality Assurance in Genetic testing. ${ }^{10}$

Validation and verification are closely related concepts that represent one of the fundamental differences between clinical and 
research laboratories. Validation and verification refer to the procedures used to confirm, through the provision of objective evidence, that a specific test performs as it should. In genetics, verification particularly concerns Conformité Européenne (European Conformity; CE)-marked in vitro diagnostic devices (IVDDs). ${ }^{33,177}$ In this regard, it confirms that within a particular laboratory the specified performance is attained. Validation is broader in scope, in that it requires an evaluation of all aspects of testing and, most importantly, accuracy: trueness and precision for quantitative tests, or sensitivity and specificity for qualitative ones. ${ }^{178}$ When a new diagnostic test is developed the laboratory must validate it, to show that it is suitable for the intended use and that it achieves the required performance. Another laboratory that implements the same test would verify locally that they obtain the same performance. Validation is a formal requirement of ISO 15189 (section 5.5.2): 'The methods and procedures selected for use shall be evaluated and found to give satisfactory results before being used for medical examinations'. In addition, many European countries have legal requirements for accreditation and or validation, ${ }^{172}$ (eg, including Belgium, Czech Republic, France, Germany and Switzerland), which unfortunately tend to be mostly poorly known and loosely enforced. A survey of usage of CE-marked IVDD assays for CFTR gene testing revealed that only one-third to one-half of respondents performed in-house verification of CE-IVDD before their use in routine diagnostics. ${ }^{172}$

The main role of EQA is to establish interlaboratory comparisons. Samples with mock clinical cases are sent to participants who test and report according to their standard practice. The accuracy of testing and reporting are evaluated. This permits independent evaluation of laboratory performance, while providing continuous education. EQA and other methods of interlaboratory comparison are a formal requirement of ISO 15189, but are rarely required by legislation.

Laboratory personnel need to be competent before performing clinical testing. Competence requires a combination of training (initial and continuous) and experience. The laboratory should perform all testing using an authorised standard operating procedure (SOP), which provides clear and easily understandable instructions for the procedure. The SOP should also provide clear instructions concerning the internal quality control requirements of the test, covering the totality of in-house procedures performed, to eliminate potential mistakes by verifying that the intended quality is achieved in each test, in every run.

The survey of QA practices in 53 European PGD laboratories revealed that only $33 \%$ of laboratories described themselves as 'accredited, certified or preparing for accreditation', and 66\% as not participating in EQA, a problem which was exacerbated at that time by the absence of existing PGD-specific schemes. ${ }^{179}$ The ESHRE PGD Consortium reacted rapidly to develop and encourage better QA, with a network of partner organisations: (a) PGD-specific EQA schemes are now available, (b) training workshops addressing the accreditation of PGD laboratories are held regularly, (c) the Consortium has formally recommended that all PGD laboratories should be accredited or working actively towards accreditation (ISO 15189) and (d) a guidance document has been published. ${ }^{150}$

A more recent survey by the EuroGentest 2 consortium of molecular genetic testing laboratories in Europe revealed that only $23 \%$ of responding laboratories were accredited, and that $22 \%$ did not participate in any genetics EQA schemes. ${ }^{180}$ More encouragingly, the quantity of accredited laboratories had doubled in 5 years. ${ }^{174}$ The OECD, ${ }^{10}$ ESHRE $^{128}$ and the CF Network ${ }^{181}$ currently recommend that all laboratories issuing genetic test results should be accredited.

\section{DTC genetic testing at the interface of genetics and reproduction} Within the healthcare domain, genetic tests are usually performed in a clinical (medical) genetics centre or other entities (public or private) recognised or certified by national healthcare systems, where due emphasis is provided on the individualised medical supervision of patients. In addition, pretest and post-test counselling (mostly performed by appropriately certified, clinical/medical geneticists, genetic counsellors or nurses), psychological follow-up and QA of genetic tests are assured. ${ }^{182}$ In contrast, within the last several years primarily commercial entities have been increasingly advertising and selling genetic tests either DTC or providing them to their customers in a 'DTC-through-physician' (ie, via a non-specialist) manner. ${ }^{183,184}$ DTC genetic testing can be defined as the advertising and selling or (free) provision of genetic tests DTCs. As suggested by the former United Kingdom Human Genetics Commission, this also includes 'tests that are commissioned by the consumer' outside the healthcare system, but where a medical practitioner or a health professional is involved in the ordering of the tests or the provision of the test result.

The range of DTC genetic tests available is broad, including for instance carrier tests for (1) rare genetic disorders, (2) 'lifestyle'related genetic traits, (3) pharmacogenomics, (4) NIPT, (5) paternity, (6) 'romantic relationship' testing, (7) genomic risk profiles for many conditions, or (8) 'recreational' ancestry or genealogical tests. ${ }^{14}$ These different types of tests bring different practical and ethical concerns. At the technical level, the different companies also use different strategies. Although various companies only look at a small number of known SNPs, others analyse 500000 or more SNPs. On the basis of the knowledge of statistical associations with genetic variants, they provide consumers with information about their susceptibility for specific health conditions or traits. ${ }^{185}$

With the decreasing prices of WES/WGS, it is expected that DTC companies will be offering WES/WGS in the near future to their clients. In particular, WGS poses ethical problems, because it basically provides complete information about an individual genome. ${ }^{186}$ This means that, potentially, every single trait or disorder ever associated in the past (or ever to be associated with in the future) with a SNP or other genomic alteration could be identified.

These tests have the potential to identify every single individual, that is, gamete donors and recipient children, that seriously challenges anonymity and privacy. ${ }^{187}$ Genomic technologies together with electronic media and communication are redefining the concept of anonymity in medicine and society. ${ }^{188}$ Another concern, highlighted by the recent case of 'racial purity testing' in Hungary ${ }^{189}$ emphasises the need for regulation and ethical governance within the scientific and/or diagnostic communities.

These developments basically compound all the ethical and social issues raised by the genetics of common multifactorial and singlegene defects. The sheer volume of novel information and the present substantial deficit of expertise to interpret and communicate this information, as well as the absence of any structured framework to manage these data, make it imperative that the ethical and social issues be addressed as soon as possible. Two types of information that can be accessed through DTC genetic testing companies are particularly challenging at the interface between genetics and reproduction: (1) carrier tests and (2) identification of relatives.

First, various commercial companies presently offer DTC carrier tests for recessive genetic disorders. ${ }^{190}$ Identifying carriers of autosomal recessive or X-linked disorders before pregnancy has the potential to benefit prospective parents. It offers carrier couples the possibility to make informed reproductive decisions before pregnancy, without the emotion and pressure associated with prenatal screening 
and offering maximum reproductive options. These include not only PND, followed (or not) by TOP or accepting the risk, but also deciding to refrain from having children, adoption, using donor sperm or eggs, and PGD. ${ }^{191}$ For example, preconception carrier screening (PCS) for CF is recommended by the American College of Medical Genetics, ${ }^{192}$ together with the American College of Obstetricians and Gynaecologists, ${ }^{193}$ for couples with no family history of this condition. ${ }^{194}$ This type of screening is not currently in practice in Europe ${ }^{195}$ within the national healthcare systems, which might accelerate implementation of commercial offers outside of them.

However, the commercial offer of carrier testing through the internet creates various challenges. First, the large number of disorders that are included in most of the panels contrasts with the limited amount of disorders that are usually suggested to be screened. The current offer challenges at least two important criteria ${ }^{196,197}$ that are usually used as the basis for population screening: (1) the condition should be an important health problem and (2) there should be a suitable test with known predictive value. Second, an internet offer provides challenges regarding provision of information, in particular whether this is sufficient, balanced, reliable and understood by the users. Third, although most companies are focused on providing online test results, they refer customers to their individual physicians or clinical genetics centres for further interpretation of test results. Not only does this disconnect such service tests from their usual embedding in a medically supervised context, as it might create a downstream effect on the healthcare system, with individuals procuring genetic counselling, this issue now seriously challenges the capacity of healthcare-based genetic services to cope with an increased influx of counselees where it is difficult to distinguish the degree of their risk. Moreover, it is not clear whether people who seek DTC testing are naturally concerned owing to their family history, or are just 'curious'. Fourth, concerns exist whether the provision of information through a website is an appropriate replacement for pre- and post-test counselling, in particular when such results include information that is difficult to interpret. Fifth, concerns revolve around the fact that DTC companies also perform genetic testing in minors. Sixth, the majority of these companies 'disclaim' any responsibility for the quality of their service, test accuracy, customer support/advice and medical implications of their results. ${ }^{198-200}$ This is in clear opposition to the ethical recommendations regarding testing minors, which emphasise delaying testing in children, unless there is a clear medical benefit for them. In the case of carrier testing, this 'should be discouraged until the minor has the maturity and competence to understand the nature of the decision and its implications, and is able to consent'. ${ }^{201}$

Finally, various companies have developed tools whereby individuals can find biological relatives via social networks or share genetic information. ${ }^{202}$ Thus, individuals can trace relatives who they might have been looking for or even might not have known existed. Success stories have been described, in which people have found firstdegree $^{203}$ or second-degree relatives. ${ }^{204}$ The more samples and information is stored by these commercial companies, the more individuals will be able to link up with distant relatives or very close relatives, such as siblings or parents. For adoptees or children conceived through gamete donation, this offers the possibility to trace unknown biological parents and other relatives. Although various countries have given up anonymity of gamete donors, ${ }^{205}$ others hold on to a model based on anonymous gamete donation. ${ }^{138}$ With increasing technical possibilities, promises with regard to anonymity of donors become increasingly difficult to fulfil.
Further debate will be necessary to discuss the implications of these techniques regarding provision of information on biological relatives to children conceived via ART or in adoptees.

\section{Epigenetic effects related to ART}

One of the recurrent questions in ART is focused on the issue as to how much this medical technology could affect the epigenome of human embryos produced in vitro. The epigenome comprises the complete set of non-covalent modifications onto the genetic material of a cell or an organism. ${ }^{206}$ These epigenetic marks or modifications correspond to molecular modifications of the DNA, such as methylation of cytosines and modification of proteins associated with DNA such as histone methylation, acetylation and deacetylation, and phosphorylation, without affecting the DNA sequence per se. Epigenetic marks often affect transcriptional activity and control developmental plasticity of cells, including cell-type-specific gene expression patterns. ${ }^{207,208}$ Epigenetics also studies alterations that may be stable throughout the lifetime of an individual. Epimutations are mitotically heritable changes not involving the DNA sequence and associate with the abnormal increase or decrease in the methylation status of a given gene, which may influence its qualitative and/or quantitative expression. Restoration of the epigenome, which is compatible with the totipotency found in the germline, requires two waves of epigenetic reprogramming: (a) during ontogeny of primordial germ cells; and (b) during preimplantation embryonic development. ${ }^{209}$ Both reprogramming events are relevant for ART, as they can interfere with the quality of gametes or be relevant to in vitro culture of human embryos.

Studies on animal models have clearly established that environmental factors, such as superovulation, culture medium composition and/or embryo manipulation, might affect the epigenome and impact on the conceptus, including neonatal birth weight. Animal models, such as mouse and cow, commonly suffer from the so-called 'large-offspring syndrome.'210-212 In humans, more studies are needed to corroborate initial discrepant observations with regard to low-birth-weight babies following ART. ${ }^{213}$ Observed phenotypic effects are mainly due to aberrant methylation and/or gene expression patterns. ${ }^{214}$ Most of the abnormally expressed genes were differentially imprinted. ${ }^{210,211,215}$

Genomic imprinting is a process through which alleles of given genes are expressed in a parent-of-origin-specific manner. Genes that are subject to imprinting often have key roles in embryonic development and behaviour. In humans, several defects in imprinted genes are linked to syndromes such as Beckwith-Wiedemann (BWS; MIM 130650), Prader-Willi (PWS; MIM 176270), Angelman (AS; MIM 105830) and Silver-Russell syndrome (SRS; MIM 180860). Increased prevalence of imprinting disorders related to ART has been reported during the last decade, but most often without proper reference to the primary cause of infertility and methods (ICSI and culture media) used in ART. Indeed, cases of BWS, AS and PWS syndromes were described after intrauterine insemination, IVF and ICSI, after fresh or frozen embryos transfers at different stages of development (days 2, 3 or 5), and following different stimulation protocols. ${ }^{21,216-218}$

A Swedish study on a large cohort of children born after IVF found seven cases of imprinting disorders (one BWS, two SRS and four PWS) out of a total of 31850 children. Among 6052 children studied through the Danish National Cohort, no imprinting disorders were reported. However, BWS and AS syndromes were not analysed in this cohort. $^{219}$ These studies need further follow-up and, most importantly, standardised methodology. 
It is possible that ART may affect the epigenome in a more general way, having different and longer-term consequences. Most prominently, inheritance of an epimutation may result in transgenerational effects, the results of which can be demonstrated only after multiple generations.

A summary of the evidence on imprinting and ART shows that absolute risks appear to be low, whereas animal studies have established their biological plausibility (see above). The influence of ART on the status of the epigenome is not yet completely understood. ${ }^{220}$ ESHRE understands and is supporting initiatives for RCTs of culture media and their impact on early epigenetic programming in the embryo. This may also be relevant when evaluating imprinting defects after ART.

Epidemiological aspects: birth defects and population genetics Although ART helps to achieve a successful pregnancy, it is associated with a slightly elevated risk of birth defects, multiple pregnancies (leading to pre- and dysmaturity) and may contribute to an increase of the genetic causes of fertility problems in the future. To evaluate the pros and cons of ART, prospective, large cohort, lifelong, multigenerational and multicentre follow-up studies would be extremely important, ${ }^{1}$ and this issue needs to be addressed at the international level.

One of the best known adverse effects of a medical treatment for the next generation are the limb-reduction defects caused by thalidomide, where the relative risk is 175.221 When considering the size of studies needed to properly evaluate potential increases of birth defects, we must realise that most monitoring programmes are limited in their ability to detect new teratogens, that is, agents which can disturb the development of an embryo or fetus. A monitoring system covering 25000 births per year could identify a 'new thalidomide-like agent' in a few weeks. ${ }^{221}$ Most drugs known to increase risks of birth defects have much lower relative risks. Thus, for valproic acid and isotretinoin, with a relative risk ranging between 20 and 25, more than 20 years of monitoring would be needed. The adverse effects of diethylstilbestrol became apparent only after a few decades, as the health effects (eg, clear-cell carcinoma and uterine anomalies) became apparent only in adulthood. ${ }^{222}$ Recent publications have mentioned imprinting disorders as a potential health effect of $\mathrm{ART}^{220}$ (see the section 'Epigenetic effects related to ART'). Here too, a long time may be needed to study the scope of their diverse health effects.

Statistical power in epidemiological studies is optimised by classifying birth defects into aetiologically homogeneous groups and expanding the sample size of the monitored population. ${ }^{221}$ Many studies evaluating the potential adverse health effects of ART present data per country and add up all birth defects, irrespective of their aetiology. Increased risks of imprinting defects, such as the BWS and AS, with a prevalence around 1:15000, will not become apparent between the total of all birth defects monitored $(2-3 \%) .^{212,220}$ Studies need to look into larger populations and into specific effects, and importantly with a standardised methodology.

In a systematic review of outcomes after ICSI, eight relevant studies were identified: two studying karyotypes and five reporting malformations. $^{220}$ In total, there were 55/1973 (2.8\%) abnormal karyotypes in the ICSI group with ejaculated sperm, $0 / 31$ in the ICSI group with epididymal sperm and 5/191 (2.6\%) in the ICSI group with testicular sperm. Major malformations were found after ICSI in 543/12377 (4.4\%) in the ejaculated sperm group, $17 / 533$ $(3.2 \%)$ in the epididymal sperm group and $31 / 670(4.6 \%)$ in the testicular sperm group. Although these show that over $95 \%$ of infants do not have these health problems, they have no statistical power to exclude an increase in specific birth defects.

Recently, a large registry-based study analysing the birth defects registry in the United States, including 1\% of ART in the population and 13500 infants with birth defects, was carried out. Among singleton births, ART was associated with septal heart defects (adjusted odds ratio $(\mathrm{aOR})=2.1 ; 95 \% \mathrm{CI}, 1.1-4.0)$, cleft lip with or without cleft palate $(\mathrm{aOR}=2.4 ; 95 \% \mathrm{CI}, 1.2-5.1)$, oesophageal atresia $(\mathrm{aOR}=4.5 ; 95 \% \mathrm{CI}, 1.9-10.5)$ and anorectal atresia $(\mathrm{aOR}=3.7 ; 95 \%$ CI, 1.5-9.1). ${ }^{223}$

Outcomes of pregnancies after IVF were studied in Sweden over a period of 25 years and revealed a decrease of multiple pregnancies, a decrease of preeclampsia and premature rupture of membranes, and an increased risk for cerebral palsy, possibly for attention-deficit and hyperactivity disorder, for impaired visual acuity and for childhood cancer, although stressing that these outcomes were generally rare, even after IVF. ${ }^{224}$

Couples using ART have, in general, a higher prevalence of aberrant karyotypes than the general population, have more mutations of the CFTR gene and show more Y chromosome microdeletions (see the section 'Genetic aspects of male fertility'). These causes of infertility may be passed onto the successive generation if medical techniques are used to achieve successful pregnancies. The main question is whether it could be considered a medical/social problem if $1 \%$ of pregnancies carry an increased risk of infertility into the next generation. If infertility treatment will be even better than it is today, these aberrant karyotypes, Y-chromosomal deletions and/or carrier of CFTR gene mutations may hardly affect the overall quality of life.

Epidemiological studies ${ }^{225}$ may help to identify and address some increased risks, such as multiple births, preterm delivery or newborn birth weight. Nonetheless, if any other increased risks could be avoided, this should become policy. Population genetic effects (ie, transgenerational effects) are mostly unknown, thus far. To decide whether or not increased risk exists, or whether or not they are avoidable or acceptable, more interdisciplinary research is needed.

Human embryonic stem cells and induced pluripotent stem cells: pitfalls and promises for regenerative medicine and disease modelling

Pluripotency is usually defined as the ability of a cell to differentiate into derivatives of the three germ layers. Human embryonic stem cells (hESC) are the best-known example of pluripotent cell lines, ${ }^{226}$ and are, for the largest part, derived from the inner cell mass of 5- to 6day-old blastocysts. These are usually originating from surplus embryos after IVF treatment. A particular example comprises hESC lines derived from embryos shown to be affected by a single-gene defect after PGD. Alternative sources have been described, such as hESC derived from a single blastomere biopsied from a cleavage-stage embryo, or from parthenogenetically activated oocytes. A major breakthrough in the field was the demonstration that terminally differentiated somatic cells, such as fibroblasts, could be reprogrammed into a pluripotent state to a great extent indistinguishable from hESC, by the induced expression of only four key pluripotency genes (OCT4, KLF4, SOX2 and C-MYC). Many observers consider these induced pluripotent stem cells (iPSC) to be the future replacement of hESC, as they do not carry the negative connotation of embryo research and embryo destruction that burden the utilisation of hESC. ${ }^{227}$

Of significant importance to researchers in the field of single-gene defects are the pluripotent cells that carry a single-gene defect. 228 hESC derived from affected PGD embryos are an important resource 
of these, but the major drawback here is that they are only available from embryos in which PGD has been performed. This approach rules out the majority of rarer single-gene defects, as well as multifactorial diseases. In contrast to hESC, iPSC can be generated from any individual that suffers from a disease of interest and several iPSC lines can be obtained from different patients with different genetic backgrounds. They can be differentiated in vitro into any tissue, including tissues that are difficult to obtain from patients, or are hard to culture such as brain tissue and cardiomyocytes. ${ }^{229}$ Thus, hESC and iPSC that carry a particular disease represent promising new disease models, especially for those single gene or multifactorial diseases for which no good animal models exist.

In past years, an increasing body of evidence has accumulated showing that hESC and iPSC suffer from genomic instability that is reminiscent of cancer cells, in particular testicular germ cell tumours. They quickly acquire trisomies, especially for chromosomes 12 and 17 , small recurrent amplifications in chromosome 20 (Spits et a ${ }^{230}$ ) and mitochondrial mutations, ${ }^{231}$ and their epigenome changes haphazardly. ${ }^{232}$ These adverse effects, on the capacity of these cells to terminally differentiate or generate possibly malignant tumours, are poorly understood. Further work is still needed to establish optimal culture conditions that prevent or limit this instability. This is of vital importance if these cells are to be used in a clinical setting and to ensure their reliability as research models. ${ }^{233}$ Concurrently, robust and higher-throughput screening tests need to be developed in order to assess the genomic/chromosomal stability of stem cells in vitro, for research, diagnostic, and eventually for therapeutic purposes.

\section{Equal access, prevention of infertility and public funding of assisted reproduction}

Although a requirement of equity, equal access to assisted reproduction for those with similar reproductive needs is still not a reality in Europe. Restrictive national legal provisions lead to increased $\mathrm{CBRC}^{23}$ (see the section 'Cross-border reproductive care') and create further barriers and social injustice. The EU and its Member State (MS) national health authorities should enable equal access to ART and PGD, as part of regular health care and favour education about infertility, genetics and reproductive options. ${ }^{25,35,233}$

Reproductive health is a great value to the community. ${ }^{234}$ Infertility and increased genetic risk for disease are serious health threats, which deserve appropriate attention and action. The primary goal of ARTs and genetics is to restore reproductive confidence for couples facing these difficulties. ${ }^{1}$ Reproductive confidence can only be communicated to the public, provided that: (1) evidence on potential risks is acquired; (2) truthful and accurate information is provided to the couples through reproductive or genetic counselling (as appropriate); and (3) quality of laboratorial and clinical services is closely monitored by accreditation and use of standard success-rate endpoints.

Prevention of infertility should become a priority goal of EU healthcare systems, in addition to social measures to counter, for example, increasing parental age, drug abuse (including tobacco and alcohol), sexually transmitted diseases, obesity, environmental factors, etc, as reviewed elsewhere for males and females. ${ }^{235-237}$ Earlier parenthood should be made easier by societal changes to facilitate the possibility of combining earlier childbearing with a successful professional career, including broad-scale education of young adults of the negative impact of ageing on reproductive performance ${ }^{237}$ and on increasing respective risks/burden. ${ }^{238}$ Economic hardship and insufficient social support for young couples have been increasing during the last decade and contribute to the tendency to postpone procreation to a later age. In general, these negative developments increase risks for pregnancy, decrease fertility (thereby increasing the need for ART) and augment the risk of transmission of chromosomal and hereditary diseases related to higher maternal and paternal age to the offspring.

Barriers to adoption as a possible alternative to assisted reproduction are still tangible and there is a lack of incentives to change this. ${ }^{239}$ A better and more widespread education about genetics (at all school levels and in society at large, educating about the role of genes, environment and other factors) should help in decreasing the concepts of genetic determinism/exceptionalism in medicine ${ }^{240}$ and of general medicalisation of life, thereby increasing the individual and social acceptance of adoption. The adequate role of genetics in healthcare systems, including promotion of public awareness on recent advances in genetics and of their impact on the general population, were comprehensively outlined in the Council of Europe (CoE) 'Recommendation CM/Rec (2010)11 of the Committee of Ministers' to MS on the impact of genetics on the organisation of healthcare services and training of health professionals, ${ }^{182}$ in the drafting of which several members of ESHG and ESHRE were involved.

On the other hand, decreased costs and (at least partial) reimbursement of hormonal stimulation and infertility treatment (if sustained under current economic pressures) may increase the uptake of ART and PGD. ${ }^{24,241}$ Access to appropriate fertility treatment should become a part of basic human rights ${ }^{242}$ for the benefit of current and future generations. ${ }^{243}$

The need for public funding of assisted reproduction can be argued in various ways. For instance, Israel's pronatalist policy of offering nearly full funding for IVF to any Israeli woman until she has two children with her current partner, is based on cultural, religious and demographic considerations. ${ }^{244}$ Recently, population policy arguments for funding IVF have also surfaced in the European debate. Following the recommendations of the 2006 RAND study, increasing the use of ART would be a means to increase fertility and thus reduce the economic costs of population aging. ${ }^{245}$ However, most accounts of whether and why society should pay for assisted reproduction refer to views about how the need for such treatment relates to notions of a fair distribution of scarce healthcare resources. ${ }^{246}$ Much of the debate has turned on how this 'need' is to be understood. Following the influential views elaborated by Daniels, ${ }^{247}$ a case for funding-assisted reproduction may be based on the notion of 'restoring equality of opportunity' by eliminating the arbitrary and undeserved effects of ill health on 'normal species functioning. On a strict reading, this line of reasoning will limit reimbursement to cases of infertility caused by a disease or a biological dysfunction. The view adopted by ESHRE's Task Force on Ethics and Law is that procreation is an important goal in life and that medical assistance to help people achieve this goal responds to a fundamental human need. ${ }^{25}$ On wider accounts of 'health', reimbursement of those dependent on such help can be justified even if their childlessness may not be caused by a disease or dysfunction. This should also include reimbursement of IVF/PGD when there is a high risk of a serious handicap or disability. On the basis of this reasoning, affluent societies can be expected to include assisted reproduction in their public funding schemes. ${ }^{170}$

Nevertheless, taking account of restricted budgets and valid claims to inclusion of other kinds of health care or other fundamental needs, rationing is inevitable, also from a justice perspective. ${ }^{25}$ Criteria for rationing may include minimal effectiveness, amount of treatments/ cycles to be reimbursed and secondary infertility/number of children. 
The application of those criteria raises difficult issues both of fairness (eg, greatest efficiency versus highest need) and of equity (eg, minimal-effectiveness threshold ideally based on all relevant factors).

The field has a responsibility to contribute to enlarging access to assisted reproduction by efforts to increase effectiveness and reduce costs, especially when services are publicly funded. Patients also have a responsibility to avoid unnecessary consumption of publicly funded health care as a result of lifestyle-related factors that are known to affect fertility and successful treatment. It is not unfair to insist that a serious effort at achieving lifestyle modification must be made before treatment can be considered. However, limiting access to publicly funded treatment because of lifestyle factors should be based on evidence rather than prejudice. ${ }^{248}$

\section{Ethical issues related to assisted reproduction and reproductive genetics}

Professionals providing reproductive treatments are not merely concerned with solving or managing a medical problem, they also causally and intentionally contribute to the birth of a child. It is generally accepted that this has implications for professional responsibilities, as, for example, reflected in the amended British Human Fertility and Embryology Act, ${ }^{249}$ where it is stated that 'treatment services shall not be provided unless account has been taken of the welfare of any child who may be born as a result'. There has been some debate about what precise standards should be used in this connection. ${ }^{250}$ ESHRE's Task Force Ethics and Law has defended a 'reasonable welfare standard', according to which fertility professionals should refrain from participating in reproduction only in cases where there would be a high risk that the future child would have a seriously diminished quality of life. ${ }^{105}$ This not only applies to situations where there are serious doubts about the psychosocial parenting capacities of those requesting help, but also to cases in which medical, including genetic, conditions would entail 'a high risk of serious harm'. For instance, how to think about cases where couples of which one of the partners is a carrier of the fully penetrant allele causing Huntington's disease (HD), ask for IVF/PGD in order to select a mutation-free child? Is providing this treatment acceptable in the light of the implications for the child of the fact that the carrier parent will inevitably develop HD? The authors of a recent review recommend to consider this on the basis of the specifics of individual cases, taking account of factors including the actual condition of the carrier (symptomatic or not yet) and the coping skills of the other partner. ${ }^{251}$

Professional co-responsibility for the welfare of the child marks an important difference between the normative framework of medically assisted reproduction and that of traditional genetic counselling, with its emphasis on professional non-directiveness. ${ }^{252}$ Whereas in PND it is generally accepted that professionals should not put any pressure on prospective parents to have PND, offering IVF on the condition of also doing PGD may be acceptable in cases where professionals would otherwise feel obliged to refrain from providing assisted reproduction. ${ }^{253}$ Possible examples are cases where the male partner carries a balanced chromosome translocation involving a high risk for the future child, or where both partners are carriers of CF or some other serious recessive disorder. Transfer decisions are a further area where different views may lead to conflicts between fertility professionals and intended parents. Most PGD centres adhere to the rule that no transfer will be done if no non-affected embryos are available. The recently updated ESHRE PGD Consortium Guidelines indicate that further specifications, for example, with regard to dynamic mutations where mutation size may have a phenotype/ genotype correlation, or with regard to embryos found to be carriers of recessive disorders, need to be explained as part of pretreatment counselling. This would ensure that couples are fully informed about how transfer decisions will be made, so that conflicts about this can be avoided. ${ }^{149}$

Since the previous joint ESHG-ESHRE position statement, ${ }^{1}$ the same ethical issues have continued to be discussed. Fundamental criticism of IVF and PGD is still raised by those who regard human embryos as having the full moral status of persons, and/or object to what they see as a philosophy of non-acceptance of the equal worth of those living with genetic disorders and handicaps. However, the tendency is one of increasing acceptance that these arguments are not convincing and that technologies allowing people with fertility problems to have their genetically own children, or allowing those at genetic risk to reproduce with confidence, should be regarded as morally valuable. That still leaves room for continuous debate about the scope of acceptable applications. Whereas in Germany legal rulings and political debate have now made PGD possible (with the first child being born in January 2012), but only for hereditary conditions that lead to miscarriage or stillbirth, ${ }^{254}$ in many other countries the range of accepted conditions has been expanded to include common disorders with a genetic predisposition that accounts for a less than complete but still high penetrance, such as hereditary cancer syndromes. Considerations behind the reasoning that conditions must be serious enough to qualify for PGD are the fact that embryo testing and selection requires burdensome and costly IVF treatment (often, in part, subsidised from public or collective funds), the moral sensitivity of embryo selection, concerns that the procedure (including embryo biopsy) may have subtle adverse long-term health effects and the fear that allowing PGD for less serious conditions would be a step on a slippery slope towards the dreaded 'designer child'. ${ }^{255,256}$

This last argument is also behind the view that PGD should be bound to a strict 'medical model', allowing only applications aimed at avoiding a (serious) health problem in the child to be. However, as the distinction between medical and non-medical allows for 'intermediate cases', a strict interpretation of this model may rule out too much. ${ }^{257}$ For instance, PGD for human leukocyte antigen typing in order to conceive a 'saviour sibling' for a child with a life-threatening disorder ${ }^{258}$ may well be morally acceptable even if PGD is not done to (also) avoid this disorder in the child to be. ${ }^{259}$ Moreover, attempts at more precisely delineating the medical model in terms of 'seriousness' should take account of the fact that this is not an entirely objective criterium, given the extent to which the seriousness of a condition depends on individual circumstances and subjective understandings. ${ }^{260}$

Ethical questions of a different kind are raised by the possible application of PGD for disorders caused by a mitochondrial DNA defect. ${ }^{261}$ Although PGD for such disorders greatly improves the probability of an unaffected pregnancy, it cannot guarantee that the child will not be affected by the very conditions that were tested for. ${ }^{262}$ This not only implies a rethinking of the traditional aim of PGD but entails difficult weighing of pros and cons in concrete cases, also in the light of a professional responsibility for the welfare of the child. ${ }^{263}$ The alternative route of maternal spindle transfer (MST) or pronuclear transfer (PNT; forms of gene-replacement therapy aimed at reconstructing eggs or one-cell embryos with healthy mitochondria) that are currently under investigation may provide a way to avoid these problems, but not without putting new ethical debates on the agenda. ${ }^{264}$ 
There is a growing awareness in the field that the introduction of new reproductive technologies requires more evidence about their efficacy, safety and cost-effectiveness than has been collected in the past, as well as long-term follow-up of clinical data. ${ }^{125}$ As stressed by ESHRE's Task Force Ethics and Law, this directly connects to the moral duty of fertility specialists to take into account the welfare of the children they help to conceive. ${ }^{105}$ A continuous and explicit commitment from the field to the ideal of responsible innovation is also a matter of societal accountability and a prerequisite for maintaining the trust of the public. ${ }^{169}$ Innovations should first be tested in preclinical animal and embryo studies for efficacy and safety, including other forms of ART. ${ }^{28,169,265,266}$ As this may also require research involving the creation of human embryos, the fact that this type of embryo research is forbidden in many countries (as well as by the European Convention on Human Rights and Biomedicine ${ }^{267}$ ) poses a hurdle for the responsible introduction of new technologies that are now on the horizon, such as MST/PNT for mitochondrial disorders and the possible reproductive use of gametes derived from pluripotent stem cells in the future. ${ }^{268}$ The reasoning behind this prohibition is difficult to sustain given the broad consensus about the relatively low moral status of the preimplantation embryo as presupposed in the justification of IVF itself. ${ }^{169}$ When, after sufficiently reassuring preclinical studies, new technologies or treatments are introduced into clinical practice, this should ideally take the form of clinical studies aimed at prospectively collecting uniform data. Large, prospective, collaborative multicentric efforts, as well as cohort studies, are strongly recommended to assess effectiveness and long-term safety, including possible transgenerational health effects (see the section 'Epigenetic effects related to ART'). Ethical, legal, social and psychological research in the field is also needed in order to reflect changes in practice and the influence of social media (web2) communication channels. ${ }^{269}$ Further research of these aspects is necessary, in particular given the rapid spread of such information/communication technologies, together with the paucity of evidence-based information websites. 270

The European Commission (EC) and MS national health authorities and funding agencies should encourage research aimed at gaining evidence on the benefits and potential risks of ART techniques, both for the future child (eg, imprinting-related disorders) and to future generations (transgenerational effects and dysgenesis due to transmission of male infertility and diseaseassociated mutations) as discussed above.

As remarked above, cascade screening is an effective strategy for identifying persons at risk of developing and transmitting genetic disorders that are highly frequent in affected families. ${ }^{271}$ This includes diseases such as hypercholesterolaemia ${ }^{272}$ and hereditary cardiac arrhythmias. ${ }^{273}$ Cascade screening has also been considered for FXS (see the section 'Genetic aspects of female infertility'). There has been some debate about the ethics of offering cascade screening in families affected by such genetic disorders. A specific concern was that the uninvited nature of the screening offer might entail an invasion of the 'right not to know' of individual family members. However, depending on the disease in question and the amount of harm that a timely warning could help avert, the 'right to know' of family members at risk may well be the morally weightier consideration. ${ }^{259}$

PCS can be a useful tool for informing couples that they may be at a high risk of having a child with an autosomal recessive disorder (eg, CF and haemoglobinopathy). As indicated above, European health systems seem hesitant to develop this option, leaving the field to commercial initiative. It can be asked whether this is wise. Given that children with these disorders are often born to non-suspecting parents, providing the option of preconception testing for carrier status of selected recessive disorders (those with a higher frequency in the specific population) could have important benefits, both in terms of providing options for reproductive choice and preventing avoidable suffering. Integrating this in a wider reproductive health policy will allow setting conditions for a qualitatively sound and ethically responsible screening offer. ${ }^{274}$ As already pointed out, technological developments will allow carrier status to be simultaneously determined for a large spectrum of recessive conditions, without significantly increasing the costs of testing 275 (see the section 'DTC genetic testing at the interface of genetics and reproduction'). The question is indeed whether or to what extent such 'comprehensive' PCS will fulfill the criteria for responsible screening (see the section 'Equal access, prevention of infertility and public funding of assisted reproduction'). Clearly, broad-scope PCS leading to couples making far-reaching reproductive decisions on the basis of test results of which the clinical implications are not yet fully understood, is morally unacceptable. $^{276}$

Another area at the interface of assisted reproduction and genetics is the selection of gamete donors, as recently reviewed, for example, by The Practice Committee of the American Society for Reproductive Medicine. ${ }^{277}$ As more diseases with a strong genetic component are now being identified, and as there are increasing technical capacities to detect them, the question arises whether the present guidelines for genetic donor screening need revision. ${ }^{278}$ Case reports of serious genetic disorders occasionally being found in donor offspring or (past) donors also lead to calls for expanded screening. ${ }^{279}$ Nevertheless, it is still uncertain how far should we could go in genetic screening of potential donors. Clearly, a 'zero-risk' approach is unrealistic and is bound to lead to false reassurance in recipients. Moreover, as this would lead to excluding most if not all donors, such an approach would be counterproductive and disproportional. Relevant ethical issues not only relate to the interests of the prospective parents and the child to be, but also to those of the donor. For instance, with the prospect of broad screening based on genome-sequencing techniques, there is a risk of findings predictive of disorders that the donor (and his close relatives) may experience as a threat without meaningful options. ${ }^{280}$ Respect for autonomy would require donors to be informed about the possible implications of testing, both for themselves and for their close relatives. A specific question concerns the scope for allowing a meaningful 'right not to know'. Counterselected donors need to be offered genetic- and reproductive counselling. Donors need not be excluded because of heterozygosity for rare ('Mendelian') autosomal recessive diseases, because they can be matched with suitable recipients. However, in this instance the cost of additional genetic testing may have an impeding role.

New ethical issues can be expected to arise as a result of the introduction of arrays and WES/WGS in the context of PGD and PGS (see the section 'PGD and PGS'). ${ }^{125,128,281}$ A possible future scenario is that the distinction between PGD for single-gene defects and PGS will disappear and that one 'universal' genome analysis will routinely be offered to all those seeking assisted reproduction, possibly in combination with preconception testing. ${ }^{282}$ From an ethical point of view, this scenario not only raises concerns about the feasibility of adequate pretest counselling and informed consent (a challenge also in other clinical contexts where new comprehensive genomic testing technologies are currently being introduced), but also requires a further rethinking of the aims of PGD/PGS. ${ }^{17,252}$ Which abnormalities, beyond those for which the couple may be at a high 
risk and/or those directly affecting treatment success, should IVF embryos be routinely tested for and why? Obviously, the fact that per cycle only a limited number of embryos will be available for selection entails that with wider testing, all embryos will in some way be 'affected'. But that does not rule out the possibility of selecting the best available embryo based on comparative genomic health profiles. Whereas some will be concerned that this brings us further on a slippery slope towards an unhealthy perfectionism, ${ }^{283}$ others have argued that prospective parents have a prima facie duty to use medical technology in order to select, from the possible children they could have, those whose lives can be expected to go best. ${ }^{284}$ How to think of the role of the fertility professional in a possible scenario of comprehensive embryo testing? Should doctors insist on using these technologies in order to ensure that after IVF, only the embryos with the best genetic make-up are allowed to grow into a child? Clearly, there is scope here for difficult conflicts between professionals and prospective parents about what tests to perform and which embryos to select.

A specific issue in this connection is that comprehensive testing of embryos may lead to finding predispositions for late-onset disorders for which no adequate options for treatment or prevention exist. Apart from the probability that one of the intended parents will have the mutation as well, a difficult problem would arise if an embryo with such a finding were to be selected for transfer. ${ }^{257}$ Arguably, the quality of life of the resulting child would be seriously affected by this knowledge. Moreover, it would be denied the right to decide for him or herself, once mature enough to do so, about what to be tested for. For both these reasons, current ESHG guidelines stipulate that predictive testing for such disorders should not be done in minors. ${ }^{198,201}$ If that is the case, would it be acceptable to bring children into the world with a positive outcome of the same kind of testing? This need not mean that embryos may not be tested for the relevant predispositions. But it would seem that such testing would only be acceptable with the aim of non-selection of carriers. Some of the moral problems of WES/WGS testing-based PGS may be avoided with the alternative strategy of offering preconception screening to prospective parents followed by targeted PGD in case of high risk. Obviously, the ethics of this approach needs further scrutiny. ${ }^{274}$

\section{Legal issues related to assisted reproduction and reproductive genetics}

Since 2006, many countries in Europe have enacted or modified laws on assisted reproduction and/or genetic testing, many of these containing provisions on PGD, taking into account the accumulating scientific knowledge and rapid development of ART techniques. Despite the general shift to more permissive regimes, major differences still exist in Europe. ${ }^{234}$ Currently PGD is banned in Austria and Switzerland, whereas jurisprudence and interpretation of laws is affecting practice in Germany, ${ }^{285}$ Ireland and Italy (see legal Acts below). Allowed indications for PGD also vary in other countries to a great extent. The diversity of regulation maintains the need for $\mathrm{CBRC}^{23}$ and is also pertinent with regards to the application of patient rights in cross-border healthcare. ${ }^{286}$

The following laws have been adopted or modified since 2006 in Europe - Belgium: Act 6/7/07; Czech Republic: Acts 227/2006Sb, 372/ 2011Sb ('Zákon o zdravotních službách') and 373/2011Sb ('Zákon o specifických zdravotních službách'); Finland: Act on Assisted reproduction 1237/2006; France: LOI no 2011-814 du 7 juillet 2011 relative à la bioéthique; Germany: Gen DG 2009 and Embryo Protection Act (1990) amendment 2011 (see above); Italy: Supreme Court Decision of 2009 modified reading of Act 2004 (Corte Constituzioale 2009,
Sentenza N. 151); ${ }^{287}$ Portugal: Act 32/2006 (Procriação medicamente assistida); Spain: Ley 14/2006 (Sobre técnicas de reproducción humana asistida); and Sweden: Lag om genetisk integritet (2006:251).

Special attention should be paid to the quality of culture media for human embryos. Safe handling is specifically dealt with by the EUTCD and the supplementing technical directives 2006/17/EC ${ }^{30}$ and $2006 / 86 / \mathrm{EC}^{31}$ that set standards on quality and safety of handling with reproductive cells, fetal tissues and cells, and adult and embryonic stem cells.

EC Directive $98 / 79 / \mathrm{EC}^{33}$ on IVDD is also applicable to genetic tests but not to in-house assays developed and used in the same facility. The manufacturer of an IVDD device must comply with the essential requirements and follow a conformity-assessment procedure of the appropriate risk category as set forth in the directive. The directive requires that manufacturers notify the competent authorities of the placing on the market of 'new products' with regard both to the technology used and the substances to be analysed or other parameters; high-density DNA probe devices (known as microchips or arrays) used in genetic screening are mentioned as particularly essential in this regard. The directive is currently under revision and it is anticipated that DTC genetic tests (see the section 'DTC genetic testing at the interface of genetics and reproduction') will be raised to a higher-risk category, meaning that they have to meet more stringent criteria in the future.

Recently, attention has been drawn to the ethical aspects of preconceptional and prenatal genomic testing in many countries, such as by the Health Council of the Netherlands ${ }^{168}$ and the Nordic Committee on Bioethics. ${ }^{288}$ The main worries relate to the lack of clinical application (within the ACCE framework (Analytic validity, Clinical validity, Clinical utility and associated Ethical, legal and social implications framework for evaluation of genetic tests) $)^{289,290}$ for the majority of tests and the fact that patients/consumers may not receive balanced pretest information. Given the size of the potential market, commercial offers may downplay the risks and exaggerate potential benefits. Moreover, genetic and reproductive health services are not ready to cope with the increasing workload, or 'flood' of preconceptional and fetal gene screening tests. ${ }^{291}$

There is accumulating case law from the European Court of Human Rights (ECHR) in the field of ART providing interesting argumentation about rights and European consensus. ${ }^{292}$ The common argument in the applications to the Court is the violation of Article 8 of the European Convention of Human Rights, ${ }^{293}$ when a procedure or reproductive treatment is refused by a national entity. This article states the following: '8.1 Everyone has the right to respect for his or her private and family life'; ' 8.2 There shall be no interference by a public authority with the exercise of this right except such as is in accordance with the law and is necessary in a democratic society in the interests of -for the protection of health and morals,....

Rulings of ECHR have constantly declared that the contracting states have a broad margin of appreciation in moral issues when European consensus does not exist, but they have to justify their approaches and strike a fair balance between competing private and public interests. One of the latest cases, $\mathrm{SH}$ and others v. Austria (ECHR 57813/00, judgement 3 November 2011), ${ }^{294}$ regarding the use of heterologous gametes for IVF, is particularly interesting in its argumentation. ${ }^{295}$ ECHR stressed the current need for a wide margin of appreciation due to sensitive moral and ethical issues against a background of fast-moving medical and scientific developments (point 97). But in point 118, ECHR stated '- this area, in which the law appears to be continuously evolving and which is subject to a particularly dynamic development in science and law, needs to be kept 
under review by the Contracting States'. This seems to be a clear message that countries cannot eternally adopt legislation against the mainstream once principles in the field of ART would become 'settled and longstanding' at a certain stage (point 96), although the mainstream is far from obvious and differences persist between European countries.

Professional societies, such as ESHG and ESHRE, have developed good practice guidance/guidelines to reflect a common understanding of the scientific, ethical, legal and social issues that are important to be acknowledged as due diligence in their field (see their websites for continuous updates). Even though such guidance has not been developed in a regular normative process by a sovereign legislator, they may gain normative legal relevance. The CoE 'Oviedo Convention' $^{267}$ (see the section 'Ethical issues related to assisted reproduction and reproductive genetics') provides a clear mechanism for making such guidelines legally relevant for the contracting states, as Article 4 requires, that 'Any intervention in the health field, including research, must be carried out in accordance with relevant professional obligations and standards'. Moreover, guidelines and guidance may become used as benchmarks for the standard of care in medical negligence actions if shown to be 'a usual and normal practice.296

Europe is still fragmented with regards to regulation on ART. The rulings of ECHR may, in time, affect somewhat the states' margin of appreciation. Until people can access services in their own countries, CBRC offers a choice, at least for motivated well-informed patients with the stamina and the necessary means.

\section{CONCLUSIONS}

The interface between ARTs and genetics has become more entwined as we increase our understanding about the genetics of infertility, and we are able to perform more comprehensive genetic testing. This continually evolving field requires communication between the clinical genetics, IVF teams and patients to ensure that they are fully informed and can make well-considered choices. The genetic basis of male and female infertility will help diagnose the cause of infertility. Moreover, against the background of reports about possible subtle health effects that may be related to epigenetic modifications, there is a growing awareness that the introduction of new reproductive technologies and treatments needs to be based on sound preclinical and clinical research aimed at collecting evidence about their efficacy and (long-term) safety, as well as their cost-effectiveness. Comprehensive genetic testing of the embryo before implantation raises complex clinical and ethical issues. Couples may increasingly undergo a whole-genome scan before an IVF (or natural) cycle, and if any serious risk is detected they can decide which reproductive option would suit them best. The possibility of performing a whole-genome scan for PGD may be around the corner and would also allow for the detection of de novo mutations. As IVF clinics gain higher success rates and genetic diagnosis helps the treatment of infertile couples, there will be need of much discussion regarding which procedures are clinically and ethically acceptable, and how these are regulated. Through these discussions, we must develop sound international policies, facilitate harmonisation of legislation and regulatory practices, including equal access to medically assisted reproduction in Europe, and beyond.

\section{ACKNOWLEDGEMENTS}

We acknowledge the support of the EuroGentest2 European Union Coordination Action project (FP7-HEALTH-F4-2010-26146). MM was supported by the Czech Ministry of Health: 00064203, NT/13770-4 and
CZ.2.16/3.1.00/24022. JS research is partly supported by PEst-C/SAU/LA0002/ 2011, from FCT, Portuguese Ministry of Education and Science. CS was supported by Flemish governmental grant FWO - Vlaanderen. This is a European Society of Human Genetics and European Society of Human Reproduction and Embryology endorsed and sponsored publication. Guest Editors: Milan Macek Jr., Joyce Harper, Joep Geraedts. Published with permission from the European Society of Human Genetics and European Society of Human Reproduction and Embryology (C) 2013, and in tandem with Human Reproduction. Copyright: European Society of Human Genetics and European Society of Human Reproduction and Embryology.

1 Soini S, Ibarreta D, Anastasiadou V et al: The interface between assisted reproductive technologies and genetics: technical, social, ethical and legal issues. Eur J Hum Genet 2006; 14: 588-645.

2 Kaariainen H: Assisted reproduction and genetics. Eur J Hum Genet 2006; 14: 505.

3 European Societies of Human Genetics and Human Reproduction and Embryology. The need for interaction between assisted reproduction technology and genetics: recommendations of the European Societies of Human Genetics and Human Reproduction and Embryology. Hum Reprod (Oxford, England) 2006; 21 1971-1973.

4 European Society of Human Genetics. The Public and Professional Policy Committee (PPPC), 2013; https://www.eshg.org/pppc.0.html. Accessed: July 2013.

5 European Society of Human Genetics, 2013; http://www.eshg.org/. Accessed: July 2013.

6 European Society of Human Reproduction and Embryology, 2013; http://www.eshre.eu/. Accessed: July 2013.

7 European Societies of Human Genetics and Human Reproduction and Embryology. The need for interaction between assisted reproduction technology and genetics. Recommendations of the European Societies of Human Genetics and Human Reproduction and Embryology. Eur J Hum Genet 2006; 14: 509-511.

8 Mastenbroek S, Twisk M, van der Veen F, Repping S: Preimplantation genetic screening: a systematic review and meta-analysis of RCTs. Hum Reprod Update 2011; 17: 454-466.

9 Yang Z, Liu J, Collins GS et al: Selection of single blastocysts for fresh transfer via standard morphology assessment alone and with array CGH for good prognosis IVF patients: results from a randomized pilot study. Mol Cytogenet 2012; 5: 24.

10 Organisation for Economic Cooperation and Development. OECD Guidelines for Quality Assurance in Molecular Genetic Testing 2007; www.oecd.org/dataoecd/43/ 6/38839788.pdf. Accessed: July 2013.

11 International Organization for Standardization: ISO 15189:2012-Medical Laboratories-Requirements for Quality and Competence. http://www.iso.org/ iso/home/store/catalogue_ics/catalogue_detail_ics.htm?csnumber=56115. Accessed: July 2013

12 Clinical Pathology Accreditation United Kingdom. http://www.cpa-uk.co.uk/. Accessed: July 2013

13 European Society of Human Genetics. Statement on direct-to-consumer genetic testing for health-related purposes. Eur J Hum Genet 2010; 18: 1271-1273.

14 Howard HC, Borry P: Europe and direct-to-consumer genetic tests. Nat Rev Genet 2011; 13: 146 author reply 146 .

15 Werner T: Next generation sequencing allows deeper analysis and understanding of genomes and transcriptomes including aspects to fertility. Reprod Fertil Dev 2011; 23: 75-80.

16 Burton $\mathrm{H}$, Cole T, Lucassen AM: Genomic medicine: challenges and opportunities for physicians. Clin Med (London, England) 2012; 12: 416-419.

17 Hens K, Dondorp W, Geraedts J, de Wert G: Comprehensive pre-implantation genetic screening: ethical reflection urgently needed. Nat Rev Genet 2012; 13: 676-677.

18 Pinborg A, Loft A, Henningsen AK, Ziebe S: Does assisted reproductive treatment increase the risk of birth defects in the offspring? Acta Obstet Gynecol Scand 2012 91: $1245-1246$

19 Davies MJ, Moore VM, Willson KJ et al: Reproductive technologies and the risk of birth defects. N Engl J Med 2012; 366: 1803-1813.

20 Halliday JL, Ukoumunne OC, Baker HW et al: Increased risk of blastogenesis birth defects, arising in the first 4 weeks of pregnancy, after assisted reproductive technologies. Hum Reprod (Oxford, England) 2010; 25: 59-65.

21 Manipalviratn S, DeCherney A, Segars J: Imprinting disorders and assisted reproductive technology. Fertil Steril 2009; 91: 305-315.

22 Harper JC, Wilton L, Traeger-Synodinos J et al: The ESHRE PGD Consortium: 10 years of data collection. Hum Reprod Update 2012; 18: 234-247.

23 Shenfield F, de Mouzon J, Pennings G et al: Cross border reproductive care in six European countries. Hum Reprod (Oxford, England) 2010; 25: 1361-1368.

24 Connolly MP, Postma MJ, Crespi S, Andersen AN, Ziebe S: The long-term fiscal impact of funding cuts to Danish public fertility clinics. Reprod Biomed Online 2011; 23: 830-837.

25 Pennings G, de Wert G, Shenfield F, Cohen J, Tarlatzis B, Devroey P: ESHRE Task Force on Ethics and Law 14: equity of access to assisted reproductive technology. Hum Reprod (Oxford, England) 2008; 23: 772-774. 
26 Kayisli UA, Seli E: Stem cells and fertility: what does the future hold? Curr Opin Obstet Gynecol 2006; 18: 338-343.

27 Harper J, Magli MC, Lundin K, Barratt CL, Brison D: When and how should new technology be introduced into the IVF laboratory? Hum Reprod (Oxford, England) 2012; 27: 303-313.

28 Brown R, Harper J: The clinical benefit and safety of current and future assisted reproductive technology. Reprod Biomed Online 2012; 25: 108-117.

29 European Commission Directive 2004/23/EC of the European Parliament and of the Council of 31 March 2004 on setting standards of quality and safety for the donation, procurement, testing, processing, preservation, storage and distribution of human tissues and cells. http://eur-lex.europa.eu/LexUriServ/LexUriServ.do?uri=OJ:L:2004:102:0048:0058:en:PDF. Accessed: July 2013

30 European Commission Directive 2006/17/EC of 8 February 2006 implementing Directive 2004/23/EC of the European Parliament and of the Council as regards certain technical requirements for the donation, procurement and testing of human tissues and cells. http://eur-lex.europa.eu/LexUriServ/LexUriServ.do?uri=OJ L:2006:038:0040:0052:EN:PDF. Accessed: July 2013.

31 European Commission Directive 2006/86/EC of 24 October 2006 implementing Directive 2004/23/EC of the European Parliament and of the Council as regards traceability requirements, notification of serious adverse reactions and events and certain technical requirements for the coding, processing, preservation, storage and distribution of human tissues and cells. http://eur-lex.europa.eu/LexUriServ/Lex UriServ.do?uri=OJ:L:2006:294:0032:0050:EN:PDF. Accessed: July 2013.

32 Willemen D, D'Hooghe T, Knoops I, De Neubourg D, Spiessens C: Does the European Union Tissues and Cells Directive improve quality in the in vitro fertilization laboratory? A case study in a tertiary referral center. Semin Reprod Med 2012; 30: 191-198.

33 European Commission Directive 98/79/EC of the European Parliament and of the Council of 27 October 1998 on in vitro diagnostic medical devices. http:// eur-lex.europa.eu/LexUriServ/LexUriServ.do?uri=OJ:L:1998:331:0001:0037:EN PDF. Accessed: July 2013

34 Blyth E, Thorn P, Wischmann T: CBRC and psychosocial counselling: assessing needs and developing an ethical framework for practice. Reprod Biomed Online 2011; 23: 642-651.

35 Pennings G, de Wert G, Shenfield F, Cohen J, Tarlatzis B, Devroey P: ESHRE task force on ethics and law 15: cross-border reproductive care. Hum Reprod (Oxford, England) 2008; 23: 2182-2184.

36 Shenfield F, Pennings G, De Mouzon J, Ferraretti AP, Goossens V: ESHRE's good practice guide for cross-border reproductive care for centers and practitioners. Hum Reprod (Oxford, England) 2011; 26: 1625-1627.

37 Dickens B: Cross-border reproductive services: FIGO Committee for the Ethical Aspects of Human Reproduction and Women's Health. Int J Gynaecol Obstet 2010; 111: 190-191.

38 European Society of Human Reproduction and Embryology. Good Clinical Treatment in Assisted Reproduction-An ESHRE position paper 2008; http://www.eshre. eu/binarydata.aspx?type=doc\&sessionld=zkky02eequx31z45nwq2otil/Good_Clinical treatment in Assisted Reproduction_ENGLISH_new.pdf. Accessed: July 2013.

39 Storrow RF: The pluralism problem in cross-border reproductive care. Hum Reprod (Oxford, England) 2010; 25: 2939-2943

40 United Kingdom Human Fertilisation \& Embryology Authority. Considering fertility treatment abroad: issues and risks 2009; http://www.hfea.gov.uk/fertility-clinicstreatment-abroad.html. Accessed: July 2013.

41 Fertility Europe. http://www.fertilityeurope.eu/. Accessed: July 2013.

42 Cobo A, Kuwayama M, Perez S, Ruiz A, Pellicer A, Remohi J: Comparison of concomitant outcome achieved with fresh and cryopreserved donor oocytes vitrified by the Cryotop method. Fertil Steril 2008; 89: 1657-1664

43 Mertes H, Pennings G, Dondorp W, de Wert G: Implications of oocyte cryostorage for the practice of oocyte donation. Hum Reprod (Oxford, England) 2012; 27: 2886-2893.

44 Foresta C, Ferlin A, Gianaroli L, Dallapiccola B: Guidelines for the appropriate use of genetic tests in infertile couples. Eur J Hum Genet 2002; 10: 303-312.

45 Beysen D, De Paepe A, De Baere E: FOXL2 mutations and genomic rearrangements in BPES. Hum Mutat 2009; 30: 158-169.

46 Calderon FR, Nelson L, Dobrowolski $P$ et al: Combination of enzyme analysis, allelespecific PCR and sequencing to detect mutations in the GALT gene. J Inherit Metab Dis 2007; 30: 818 .

47 Tong ZB, Sullivan SD, Lawless LM, Vanderhoof V, Zachman K, Nelson LM: Five mutations of mitochondrial DNA polymerase-gamma (POLG) are not a prevalent etiology for spontaneous 46,XX primary ovarian insufficiency. Fertil Steril 2010; 94 : 2932-2934

48 De Vos M, Devroey P, Fauser BC: Primary ovarian insufficiency. Lancet 2010; 376: 911-921.

49 Persani L, Rossetti R, Cacciatore C: Genes involved in human premature ovarian failure. J Mol Endocrinol 2010; 45: 257-279.

50 Cadman SM, Kim SH, Hu Y, Gonzalez-Martinez D, Bouloux PM: Molecular pathogenesis of Kallmann's syndrome. Hormone Res 2007; 67: 231-242.

51 Hughes IA, Werner R, Bunch T, Hiort O: Androgen insensitivity syndrome. Semin Reprod Med 2012; 30: 432-442.

52 European Society of Human Reproduction and Embryology. Genetic aspects of female reproduction, proceedings from the Capri Workshop Group. Hum Reprod Update 2008; 14: 293-307.

53 Rull K, Nagirnaja L, Laan M: Genetics of recurrent miscarriage: challenges, current knowledge, future directions. Front Genet 2012; 3: 34.
54 McNamee K, Dawood F, Farquharson R: Recurrent miscarriage and thrombophilia: an update. Curr Opin Obstet Gynecol 2012; 24: 229-234.

55 Hunter JE, Epstein MP, Tinker SW, Charen KH, Sherman SL: Fragile X-associated primary ovarian insufficiency: evidence for additional genetic contributions to severity. Genet Epidemiol 2008; 32: 553-559.

56 Keymolen K, Staessen C, Verpoest W et al: A proposal for reproductive counselling in carriers of Robertsonian translocations: 10 years of experience with preimplantation genetic diagnosis. Hum Reprod (Oxford, England) 2009; 24: 2365-2371.

57 Keymolen K, Staessen C, Verpoest W, Liebaers I, Bonduelle M: Preimplantation genetic diagnosis in female and male carriers of reciprocal translocations: clinical outcome until delivery of 312 cycles. Eur J Hum Genet 2012; 20: 376-380.

58 Koika V, Georgopoulos NA, Piouka A et al: Increased frequency of the DI genotype of the angiotensin-I converting enzyme and association of the II genotype with insulin resistance in polycystic ovary syndrome. Eur J Endocrinol 2012; 166: 695-702.

59 Rahmioglu N, Missmer SA, Montgomery GW, Zondervan KT: Insights into assessing the genetics of endometriosis. Curr Obstet Gynecol Rep 2012; 1: 124-137.

60 Sykiotis GP, Pitteloud N, Seminara SB, Kaiser UB, Crowley WF Jr: Deciphering genetic disease in the genomic era: the model of GnRH deficiency. Sci Trans Med 2010; 2: 32rv32

61 Cooper TG, Noonan E, von Eckardstein S et al: World Health Organization reference values for human semen characteristics. Hum Reprod Update 2010; 16: 231-245.

62 Krausz C: Male infertility: pathogenesis and clinical diagnosis. Best Pract Res Clin Endocrinol Metab 2011; 25: 271-285

63 Tournaye H: Update on surgical sperm recovery-the European view. Hum Fertil (Camb) 2010; 13: 242-246.

64 Stahl PJ, Schlegel PN: Genetic evaluation of the azoospermic or severely oligozoospermic male. Curr Opin Obstet Gynecol 2012; 24: 221-228.

65 Dul EC, Groen H, van Ravenswaaij-Arts CM, Dijkhuizen T, van Echten-Arends J, Land JA: The prevalence of chromosomal abnormalities in subgroups of infertile men. Hum Reprod (Oxford, England) 2012; 27: 36-43.

66 Maiburg M, Repping S, Giltay J: The genetic origin of Klinefelter syndrome and its effect on spermatogenesis. Fertil Steril 2012; 98: 253-260.

67 Herlihy AS, Halliday JL, Cock ML, McLachlan RI: The prevalence and diagnosis rates of Klinefelter syndrome: an Australian comparison. Med J Aust 2011; 194: 24-28.

68 Yarali H, Polat M, Bozdag G et al: TESE-ICSI in patients with non-mosaic Klinefelter syndrome: a comparative study. Reprod Biomed Online 2009; 18: 756-760.

69 Gies I, De Schepper J, Goossens E, Van Saen D, Pennings G, Tournaye H: Spermatogonial stem cell preservation in boys with Klinefelter syndrome: to bank or not to bank, that's the question. Fertil Steril 2012; 98: 284-289.

70 Madan K: Balanced complex chromosome rearrangements: reproductive aspects. A review. Am J Med Genet A 2012; 158A: 947-963.

71 Xu WM, Shi QX, Chen WY et al: Cystic fibrosis transmembrane conductance regulator is vital to sperm fertilizing capacity and male fertility. Proc Natl Acad Sci USA 2007; 104: 9816-9821.

72 Yu J, Chen Z, Ni Y, Li Z: CFTR mutations in men with congenital bilateral absence of the vas deferens (CBAVD): a systemic review and meta-analysis. Hum Reprod (Oxford, England) 2012; 27: 25-35.

73 Daudin M, Bieth E, Bujan L, Massat G, Pontonnier F, Mieusset R: Congenital bilateral absence of the vas deferens: clinical characteristics, biological parameters, cystic fibrosis transmembrane conductance regulator gene mutations, and implications for genetic counseling. Fertil steril 2000; 74: 1164-1174.

74 Tuttelmann F, Werny F, Cooper TG, Kliesch S, Simoni M, Nieschlag E: Clinical experience with azoospermia: aetiology and chances for spermatozoa detection upon biopsy. Int J Androl 2011; 34: 291-298.

75 Schwarzer JU, Schwarz M: Significance of CFTR gene mutations in patients with congenital aplasia of vas deferens with special regard to renal aplasia. Andrologia 2012; 44: 305-307.

76 Simoni M, Tuttelmann F, Gromoll J, Nieschlag E: Clinical consequences of microdeletions of the $Y$ chromosome: the extended Munster experience. Reprod Biomed Online 2008; 16: 289-303.

77 Simoni M, Bakker E, Krausz C: EAA/EMQN best practice guidelines for molecular diagnosis of $y$-chromosomal microdeletions. State of the art 2004. Int J Androl 2004; 27: 240-249.

78 McLachlan RI, O'Bryan MK: Clinical Review\#: State of the art for genetic testing of infertile men. J Clin Endocrinol Metab 2010; 95: 1013-1024.

79 Repping S, van Daalen SK, Korver CM et al: A family of human Y chromosomes has dispersed throughout northern Eurasia despite a 1.8-Mb deletion in the azoospermia factor c region. Genomics 2004; 83: 1046-1052.

80 Navarro-Costa P, Plancha CE, Goncalves J: Genetic dissection of the AZF regions of the human Y chromosome: thriller or filler for male (in)fertility? J Biomed Biotechnol 2010; 2010: 936569.

81 Rozen SG, Marszalek JD, Irenze K et al: AZFc deletions and spermatogenic failure: a population-based survey of 20,000 Y chromosomes. Am J Hum Genet 2012; 91 : 890-896.

82 Patrat C, Bienvenu T, Janny L et al: Clinical data and parenthood of 63 infertile and Y-microdeleted men. Fertil Steril 2010; 93: 822-832.

83 Visser L, Westerveld GH, Korver CM et al: Y chromosome gr/gr deletions are a risk factor for low semen quality. Hum Reprod (Oxford, England) 2009; 24: 2667-2673

84 Kim HG, Bhagavath B, Layman LC: Clinical manifestations of impaired GnRH neuron development and function. Neurosignals 2008; 16: 165-182. 
85 Sato N: Genetics of male hypogonadotropic hypogonadism. Pediatr Endocrinol Rev 2012; 10(Suppl 1): 110-125.

86 Hardelin JP, Dode C: The complex genetics of Kallmann syndrome: KAL1, FGFR1, FGF8, PROKR2, PROK2, et al. Sex Dev 2008; 2: 181-193.

87 Sykiotis GP, Plummer L, Hughes VA et al: Oligogenic basis of isolated gonadotropinreleasing hormone deficiency. Proc Natl Acad Sci USA 2010; 107: 15140-15144.

88 Ferlin A, Vinanzi C, Garolla A et al: Male infertility and androgen receptor gene mutations: clinical features and identification of seven novel mutations. Clin Endocrinol 2006; 65: 606-610.

89 Tuttelmann F, Rajpert-De Meyts E, Nieschlag E, Simoni M: Gene polymorphisms and male infertility - a meta-analysis and literature review. Reprod Biomed Online 2007; 15: 643-658.

90 Kosova G, Scott NM, Niederberger C, Prins GS, Ober C: Genome-wide association study identifies candidate genes for male fertility traits in humans. Am J Hum Genet 2012; 90: 950-961.

$91 \mathrm{Hu}$ Z, Xia Y, Guo X et al: A genome-wide association study in Chinese men identifies three risk loci for non-obstructive azoospermia. Nat Genet 2012; 44: 183-186.

92 Perrin A, Coat C, Nguyen $\mathrm{MH}$ et al: Molecular cytogenetic and genetic aspects of globozoospermia: a review. Andrologia 2013; 45: 1-9.

93 Molinari E, Mirabelli M, Raimondo S et al: Sperm macrocephaly syndrome in a patient without AURKC mutations and with a history of recurrent miscarriage. Reprod Biomed Online 2013; 26: 148-156.

94 Nakada K, Sato A, Yoshida K et al: Mitochondria-related male infertility. Proc Nat/ Acad Sci USA 2006; 103: 15148-15153.

95 Tuttelmann F, Simoni M, Kliesch S et al: Copy number variants in patients with severe oligozoospermia and Sertoli-cell-only syndrome. PloS One 2011; 6: e19426.

96 Du Plessis SS, Cabler S, McAlister DA, Sabanegh E, Agarwal A: The effect of obesity on sperm disorders and male infertility. Nat Rev Urol 2010; 7: 153-161.

97 Giwercman A, Rylander L, Lundberg Giwercman Y: Influence of endocrine disruptors on human male fertility. Reprod Biomed Online 2007; 15: 633-642.

98 Merhi ZO: Challenging cell phone impact on reproduction: a review. J Assist Reprod Genet 2012; 29: 293-297.

99 Aston KI, Conrad DF: A review of genome-wide approaches to study the genetic basis for spermatogenic defects. Methods Mol Biol (Clifton, NJ) 2013; 927: 397-410.

100 Zawati MH, Knoppers BM: International normative perspectives on the return of individual research results and incidental findings in genomic biobanks. Genet Med 2012; 14: 484-489.

101 Baker MA, Nixon B, Naumovski N, Aitken RJ: Proteomic insights into the maturation and capacitation of mammalian spermatozoa. Syst Biol Reprod Med 2012; 58 211-217.

102 Pastuszak AW, Lamb DJ: The genetics of male fertility-from basic science to clinical evaluation. J Androl 2012; 33: 1075-1084.

103 Rantanen E, Hietala M, Kristoffersson $\mathrm{U}$ et al: What is ideal genetic counselling? A survey of current international guidelines. Eur J Hum Genet 2008; 16 $445-452$.

104 Desmyttere S, De Rycke M, Staessen C et al: Neonatal follow-up of 995 consecutively born children after embryo biopsy for PGD. Hum Reprod (Oxford, England) 2012; 27: 288-293.

105 Pennings G, de Wert G, Shenfield F, Cohen J, Tarlatzis B, Devroey P: ESHRE Task Force on Ethics and Law 13: the welfare of the child in medically assisted reproduction. Hum Reprod (Oxford, England) 2007; 22: 2585-2588.

106 Johnson MH: Robert Edwards: the path to IVF. Reprod Biomed Online 2011; 23 245-262.

107 American Society of Human Genetics. Genetic counseling. Am J Hum Genet 1975; 27: 240-242.

108 Resta R, Biesecker BB, Bennett RL et al: A new definition of genetic counseling National Society of Genetic Counselors' Task Force report. J Genet Counsel 2006; 15: 77-83.

109 Skirton H, Lewis C, Kent A, Coviello DA: Genetic education and the challenge of genomic medicine: development of core competences to support preparation of health professionals in Europe. Eur J Hum Genet 2010; 18: 972-977.

110 Skirton H, Patch C, Voelckel MA: Using a community of practice to develop standards of practice and education for genetic counsellors in Europe. J Commun Genet 2010; 1: 169-173.

111 Grace KS, Sinclair KD: Assisted reproductive technology, epigenetics, and long-term health: a developmental time bomb still ticking. Semin Reprod Med 2009; 27 409-416.

112 McGillivray G, Rosenfeld JA, McKinlay Gardner RJ, Gillam LH: Genetic counselling and ethical issues with chromosome microarray analysis in prenatal testing. Prenat Diagn 2012; 32: 389-395.

113 Castellani C, Cuppens H, Macek M Jr et al: Consensus on the use and interpretation of cystic fibrosis mutation analysis in clinical practice. J Cyst Fibros 2008; 7: 179-196.

114 Johns Hopkins University School of Medicine Baltimore. Clinical and Functiona Translation of CFTR (CFTR2). http://www.cftr2.org. Accessed: July 2013.

115 Karatas JC, Barlow-Stewart K, Strong KA, Meiser B, McMahon C, Roberts C Women's experience of pre-implantation genetic diagnosis: a qualitative study. Prenat Diagn 2010; 30: 771-777.

116 Hershberger PE, Pierce PF: Conceptualizing couples' decision making in PGD: emerging cognitive, emotional, and moral dimensions. Patient Educ Counsel 2010 81: 53-62.

117 Hershberger PE, Gallo AM, Kavanaugh K, Olshansky E, Schwartz A, Tur-Kaspa I: The decision-making process of genetically at-risk couples considering preimplantation genetic diagnosis: initial findings from a grounded theory study. Soc Sci Med 2012 74: 1536-1543.

118 Speechley KN, Nisker J: Preimplantation genetic diagnosis in Canada: a survey of Canadian IVF units. J Obstet Gynaecol 2010; 32: 341-347.

119 Harton GL, Magli MC, Lundin K et al: ESHRE PGD Consortium/Embryology Specia Interest Group-best practice guidelines for polar body and embryo biopsy for preimplantation genetic diagnosis/screening (PGD/PGS). Hum Reprod (Oxford, England) 2011; 26: 41-46.

120 Xu K, Montag M: New perspectives on embryo biopsy: not how, but when and why? Sem Reprod Med 2012; 30: 259-266.

121 Goossens V, Traeger-Synodinos J, Coonen E et al: ESHRE PGD Consortium data collection XI: cycles from January to December 2008 with pregnancy follow-up to October 2009. Hum Reprod (Oxford, England) 2012; 27: 1887-1911.

122 Kokkali G, Vrettou C, Traeger-Synodinos J et al: Birth of a healthy infant following trophectoderm biopsy from blastocysts for PGD of beta-thalassaemia major. Hum Reprod (Oxford, England) 2005; 20: 1855-1859.

123 McArthur SJ, Leigh D, Marshall JT, de Boer KA, Jansen RP: Pregnancies and live births after trophectoderm biopsy and preimplantation genetic testing of human blastocysts. Fertil Steril 2005; 84: 1628-1636.

124 Youssry M, Ozmen B, Zohni K, Diedrich K, Al-Hasani S: Current aspects of blastocyst cryopreservation. Reprod Biomed Online 2008; 16: 311-320.

125 Harper JC, Sengupta SB: Preimplantation genetic diagnosis: state of the art 2011 Hum Genet 2012; 131: 175-186.

126 Harton GL, De Rycke M, Fiorentino F et al: ESHRE PGD consortium best practice guidelines for amplification-based PGD. Hum Reprod (Oxford, England) 2011; 26 33-40.

127 Harton GL, Harper JC, Coonen E et al: ESHRE PGD Consortium best practice guidelines for fluorescence in situ hybridization-based PGD. Hum Reprod (Oxford, England) 2011; 26: 25-32.

128 Harper JC, Harton G: The use of arrays in preimplantation genetic diagnosis and screening. Fertil Steril 2010; 94: 1173-1177.

129 Wilton L, Thornhill A, Traeger-Synodinos J, Sermon KD, Harper JC: The causes of misdiagnosis and adverse outcomes in PGD. Hum Reprod (Oxford, England) 2009, 24: $1221-1228$.

130 Renwick P, Trussler J, Lashwood A, Braude P, Ogilvie CM: Preimplantation genetic haplotyping: 127 diagnostic cycles demonstrating a robust, efficient alternative to direct mutation testing on single cells. Reprod Biomed Online 2010; 20: 470-476.

131 Fragouli E, Wells D: Aneuploidy in the human blastocyst. Cytogenet Genome Res 2011; 133: 149-159.

132 Gutierrez-Mateo C, Colls P, Sanchez-Garcia J et al: Validation of microarray comparative genomic hybridization for comprehensive chromosome analysis of embryos. Fertil Steril 2011; 95: 953-958.

133 Alfarawati S, Fragouli E, Colls P, Wells D: First births after preimplantation genetic diagnosis of structural chromosome abnormalities using comparative genomic hybridization and microarray analysis. Hum Reprod (Oxford, England) 2011; 26 1560-1574.

134 Fiorentino F, Spizzichino L, Bono S et al: PGD for reciprocal and Robertsonian translocations using array comparative genomic hybridization. Hum Reprod (Oxford, England) 2011; 26: 1925-1935

135 Treff NR, Northrop LE, Kasabwala K, Su J, Levy B, Scott RT Jr: Single nucleotide polymorphism microarray-based concurrent screening of 24-chromosome aneuploidy and unbalanced translocations in preimplantation human embryos. Fertil Steril 2011; 95: 1606-1612, e1601-e1602.

136 Handyside $\mathrm{AH}$, Harton GL, Mariani B et al: Karyomapping: a universal method for genome wide analysis of genetic disease based on mapping crossovers between parental haplotypes. J Med Genet 2010; 47: 651-658.

137 Brezina PR, Benner A, Rechitsky S et al: Single-gene testing combined with single nucleotide polymorphism microarray preimplantation genetic diagnosis for aneuploidy: a novel approach in optimizing pregnancy outcome. Fertil Steril 2011 95: 1786, e1785-e1788.

138 Frith L: Gamete donation and anonymity: the ethical and legal debate. Hum Reprod (Oxford, England) 2001; 16: 818-824.

139 Liang D, Lv W, Wang $\mathrm{H}$ et al: Non-invasive prenatal testing of fetal whole chromosome aneuploidy by massively parallel sequencing. Prenat Diagn 2013; 33: 409-415.

140 Wilson KL, Czerwinski JL, Hoskovec JM et al: NSGC Practice Guideline: prenatal screening and diagnostic testing options for chromosome aneuploidy. J Genet Counsel 2012; 22: 4-15.

141 Lemke A, Bick D, Dimmock D, Simpson P, Veith R: Perspectives of clinical genetics professionals toward genome sequencing and incidental findings: a survey study. Clin Genet 2012; 84: 230-236.

142 Pergament E, Pergament D: Reproductive decisions after fetal genetic counselling Best Pract Res Clin Obstet Gynaecol 2012; 26: 517-529.

143 Geraedts J, Collins J, Gianaroli L et al: What next for preimplantation genetic screening? A polar body approach! Hum Reprod (Oxford, England) 2010; 25: 575-577.

144 Geraedts JP: Does additional hybridization also improve preimplantation genetic screening results? Exp Rev Mol Diagn 2010; 10: 981-985.

145 Harper J, Coonen $\mathrm{E}$, De Rycke $\mathrm{M}$ et al: What next for preimplantation genetic screening (PGS)? A position statement from the ESHRE PGD Consortium Steering Committee. Hum Reprod (Oxford, England) 2010; 25: 821-823.

146 Geraedts J, Montag M, Magli MC et al: Polar body array CGH for prediction of the status of the corresponding oocyte. Part I: clinical results. Hum Reprod (Oxford, England) $2011 ; 26$ : 3173-3180 
147 Scott Jr RT, Ferry K, Su J, Tao X, Scott K, Treff NR: Comprehensive chromosome screening is highly predictive of the reproductive potential of human embryos: a prospective, blinded, nonselection study. Fertil Steril 2012; 97: 870-875.

148 Harper JC, Wilton L, Traeger-Synodinos J et al: The ESHRE PGD Consortium: ten years of data collection May-Jun; 18: 234-247.

149 Harton G, Braude P, Lashwood A et al: ESHRE PGD consortium best practice guidelines for organization of a PGD centre for PGD/preimplantation genetic screening. Hum Reprod (Oxford, England) 2011; 26: 14-24.

150 Harper JC, Sengupta S, Vesela K et al: Accreditation of the PGD laboratory. Hum Reprod (Oxford, England) 2010; 25: 1051-1065.

151 de Jong A, Dondorp WJ, de Die-Smulders CE, Frints SG, de Wert GM: Non-invasive prenatal testing: ethical issues explored. Eur J Hum Genet 2010; 18: 272-277.

152 Delhanty JD, Griffin DK, Handyside AH et al: Detection of aneuploidy and chromosomal mosaicism in human embryos during preimplantation sex determination by fluorescent in situ hybridisation, (FISH). Hum Mol Genet 1993; 2: 1183-1185

153 Munne S, Grifo J, Cohen J, Weier HU: Chromosome abnormalities in human arrested preimplantation embryos: a multiple-probe FISH study. Am J Hum Genet 1994; 55: 150-159.

154 Iwarsson $\mathrm{E}$, Lundqvist $\mathrm{M}$, Inzunza J et al: A high degree of aneuploidy in frozenthawed human preimplantation embryos. Hum Genet 1999; 104: 376-382.

155 Hodes-Wertz B, Grifo J, Ghadir S et al: Idiopathic recurrent miscarriage is caused mostly by aneuploid embryos. Fertil Steril 2012; 98: 675-680.

156 Munne S, Sandalinas M, Magli C, Gianaroli L, Cohen J, Warburton D: Increased rate of aneuploid embryos in young women with previous aneuploid conceptions. Prenat Diagn 2004; 24: 638-643.

157 Baart EB, Martini E, van den Berg I et al: Preimplantation genetic screening reveals a high incidence of aneuploidy and mosaicism in embryos from young women undergoing IVF. Hum Reprod (Oxford, England) 2006; 21: 223-233.

158 van Echten-Arends J, Mastenbroek S, Sikkema-Raddatz B et al: Chromosomal mosaicism in human preimplantation embryos: a systematic review. Hum Reprod Update $2011 ; 17:$ 620-627

159 Vanneste $\mathrm{E}$, Voet $\mathrm{T}$, Le Caignec $\mathrm{C}$ et al: Chromosome instability is common in human cleavage-stage embryos. Nat Med 2009; 15: 577-583.

160 Vanneste E, Bittman L, Van der Aa N, Voet T, Vermeesch JR: New array approaches to explore single cells genomes. Front Genet 2012; 3: 44

161 Voullaire L, Collins V, Callaghan T, McBain J, Williamson R, Wilton L: High incidence of complex chromosome abnormality in cleavage embryos from patients with repeated implantation failure. Fertil Steril 2007; 87: 1053-1058.

162 Wells D, Delhanty JD: Comprehensive chromosomal analysis of human preimplantation embryos using whole genome amplification and single cell comparative genomic hybridization. Mol Hum Reprod 2000; 6: 1055-1062.

163 Daphnis DD, Fragouli E, Economou K et al: Analysis of the evolution of chromosome abnormalities in human embryos from Day 3 to 5 using CGH and FISH. Mol Hum Reprod 2008; 14: 117-125

164 Rius M, Obradors A, Daina G et al: Detection of unbalanced chromosome segregations in preimplantation genetic diagnosis of translocations by short comparative genomic hibridization. Fertil Steril 2011; 96: 134-142.

165 Voet T, Vanneste E, Van der Aa N et al: Breakage-fusion-bridge cycles leading to inv dup del occur in human cleavage stage embryos. Hum Mutat 2011; 32 783-793.

166 Spencer TE, Palmarini M: Application of next generation sequencing in mammalian embryogenomics: lessons learned from endogenous betaretroviruses of sheep. Anim Reprod Sci 2012; 134: 95-103.

167 Navin N, Kendall J, Troge J et al: Tumour evolution inferred by single-cell sequencing. Nature 2011; 472: 90-94.

168 Dondorp WJ, de Wert GM: The 'thousand-dollar genome': an ethical exploration. Eur J Hum Genet 2013; 21(Suppl 1): S6-S26.

169 Dondorp W, de Wert G: Innovative reproductive technologies: risks and responsibilities. Hum Reprod (Oxford, England) 2011; 26: 1604-1608.

170 Pennings G, Mertes $\mathrm{H}$ : Ethical issues in infertility treatment. Best Pract Res Clin Obstet Gynaecol 2012; 26: 853-863.

171 Seneca S, Morris MA, Patton S, Elles R, Sequeiros J: Experience and outcome of 3 years of a European EQA scheme for genetic testing of the spinocerebellar ataxias. Eur J Hum Genet 2008; 16: 913-920.

172 Patton SJ, Wallace AJ, Elles R: Benchmark for evaluating the quality of DNA sequencing: proposal from an international external quality assessment scheme. Clin Chem 2006; 52: 728-736.

173 Touitou I, Rittore C, Philibert L, Yague J, Shinar Y, Aksentijevich I: An international external quality assessment for molecular diagnosis of hereditary recurrent fevers: a 3-year scheme demonstrates the need for improvement. Eur J Hum Genet 2009; 17: 890-896.

174 Berwouts S, Fanning K, Morris MA, Barton DE, Dequeker E: Quality assurance practices in Europe: a survey of molecular genetic testing laboratories. Eur J Hum Genet 2012; 20: 1118-1126.

175 Hastings RJ, Maher EJ, Quellhorst-Pawley B, Howell RT: An Internet-based external quality assessment in cytogenetics that audits a laboratory's analytical and interpretative performance. Eur J Hum Genet 2008; 16: 1217-1224.

176 International Organization for Standardization-ISO 9001 2008; http://www.iso.org/ iso/catalogue_detail?csnumber $=46486$. Accessed: July 2013.

177 Camajova J, Berwouts S, Matthijs G, Macek Jr M, Dequeker E: Variability in the use of CE-marked assays for in vitro diagnostics of CFTR gene mutations in European genetic testing laboratories. Eur J Hum Genet 2009; 17: 537-540.
178 Mattocks CJ, Morris MA, Matthijs G et al: A standardized framework for the validation and verification of clinical molecular genetic tests. Eur J Hum Genet 2010; 18: $1276-1288$

179 Corveleyn A, Morris MA, Dequeker E et al: Provision and quality assurance of preimplantation genetic diagnosis in Europe. Eur J Hum Genet 2008; 16: 290-299.

180 Eurogentest2 Concerted Action. www.eurogentest.org. Accessed: July 2013

181 Dequeker E, Stuhrmann M, Morris MA et al: Best practice guidelines for molecular genetic diagnosis of cystic fibrosis and CFTR-related disorders-updated European recommendations. Eur J Hum Genet 2009; 17: 51-65.

182 Council of Europe. Recommendation $\mathrm{CM} / \operatorname{Rec}(2010) 11$ of the Committee of Ministers to member states on the impact of genetics on the organisation of health care services and training of health professionals. https://wcd.coe.int/ViewDoc. jsp?id=1660977\&Site=COE. Accessed: July 2013.

183 Hunter DJ, Khoury MJ, Drazen JM: Letting the genome out of the bottle-will we get our wish? N Engl J Med 2008; 358: 105-107.

184 European Academies of Science Advisory Council and Federation of European Academies of Medicine. Direct-to-consumer genetic testing 2012; http://www.easac.eu/fileadmin/PDF_s/reports_statements/Easac_12_DTCGT-Lay_Web.pdf. Accessed: July 2013.

185 Borry P, Howard H: DTC genetic services: a look across the pond. Am J Bioethics 2008; 8: 14-16.

186 Su Y, Howard HC, Borry P: Users' motivations to purchase direct-to-consumer genome-wide testing: an exploratory study of personal stories. J Commun Genet 2011; 2: 135-146.

187 Greenbaum D, Du J, Gerstein M: Genomic anonymity: have we already lost it? Am J Bioethics 2008; 8: 71-74.

188 Schadt EE: The changing privacy landscape in the era of big data. Mol Syst Bio 2012; 8: 612 .

189 Abbott A: Genome test slammed for assessing 'racial purity'. Nature 2012; 486: 167

190 Borry P, Henneman L, Lakeman P, ten Kate LP, Cornel MC, Howard HC: Preconceptional genetic carrier testing and the commercial offer directly-to-consumers. Hum Reprod (Oxford, England) 2011; 26: 972-977.

191 Lakeman P, Plass AM, Henneman L, Bezemer PD, Cornel MC, ten Kate LP: Three-month follow-up of Western and non-Western participants in a study on preconceptional ancestry-based carrier couple screening for cystic fibrosis and hemoglobinopathies in the Netherlands. Genet Med 2008; 10: 820-830.

192 American College of Medical Genetics and Genomics. www.acmg.net. Accessed: July 2013

193 American College of Obstetricians and Gynecologists. http://www.acog.org/. Accessed: July 2013.

194 Watson MS, Cutting GR, Desnick RJ et al: Cystic fibrosis population carrier screening: 2004 revision of American College of Medical Genetics mutation panel. Genet Med 2004; 6: 387-391.

195 Castellani C, Macek Jr M, Cassiman JJ et al: Benchmarks for cystic fibrosis carrier screening: a European consensus document. J Cyst Fibros 2010; 9: 165-178.

196 European Society of Human Genetics. Population genetic screening programmes: technical, social and ethical issues. Eur J Hum Genet 2003; 11(Suppl 2): S5-S7.

197 Health Council of the Netherlands Advisory report - Screening: between hope and hype 2008; http://www.gezondheidsraad.nl/sites/default/files/200805E_0.pdf. Accessed: July 2013

198 Borry P, Howard HC, Senecal K, Avard D: Direct-to-consumer genome scanning services. Also for children? Nat Rev Genet 2009; 10: 8.

199 Borry P, Howard HC, Senecal K, Avard D: Health-related direct-to-consumer genetic testing: a review of companies' policies with regard to genetic testing in minors. Fam Cancer 2010; 9: 51-59.

200 Howard HC, Avard D, Borry P: Are the kids really all right? Direct-to-consumer genetic testing in children: are company policies clashing with professional norms? Eur J Hum Genet 2011; 19: 1122-1126.

201 European Society of Human Genetics. Genetic testing in asymptomatic minors: recommendations of the European Society of Human Genetics. Eur J Hum Genet 2009; 17: 720-721.

202 Lee SS, Crawley L: Research 2.0: social networking and direct-to-consumer (DTC) genomics. Am J Bioethics 2009; 9: 35-44.

203 The Family Tree DNA: Richard Hill's Story 2012; http://www.familytreedna.com/ landing/richard-hill.aspx. Accessed: July 2013.

204 Stories From 23andMe Blog: 'Hey, Bro' 2011; http://blog.23andme.com/23andmecustomer-stories/stories-from-23andme-neil-schwartzman/. Accessed: July 2013.

205 Sauer JL: Competing interests and gamete donation: the case for anonymity. Seton Hall Law Rev 2009; 39: 919-954.

206 Yuan GC: Linking genome to epigenome. Wiley Interdisc Rev Syst Biol Med 2012; 4: 297-309.

207 Jablonka E, Raz G: Transgenerational epigenetic inheritance: prevalence, mechanisms, and implications for the study of heredity and evolution. Quarter Rev Bio 2009; 84: 131-176.

208 van Montfoort AP, Hanssen LL, de Sutter P, Viville S, Geraedts JP, de Boer P: Assisted reproduction treatment and epigenetic inheritance. Hum Reprod Update 2012; 18: 171-197.

209 Feng S, Jacobsen SE, Reik W: Epigenetic reprogramming in plant and animal development. Science (New York, NY) 2010; 330: 622-627.

210 Khosla S, Dean W, Brown D, Reik W, Feil R: Culture of preimplantation mouse embryos affects fetal development and the expression of imprinted genes. Biol Reprod 2001; 64: 918-926. 
211 Young LE, Fernandes K, McEvoy TG et al: Epigenetic change in IGF2R is associated with fetal overgrowth after sheep embryo culture. Nat Genet 2001; 27: $153-154$.

212 Velker BA, Denomme MM, Mann MR: Embryo culture and epigenetics. Methods Mol Biol (Clifton, NJ) 2012; 912: 399-421.

213 Dumoulin JC, Land JA, Van Montfoort AP et al: Effect of in vitro culture of human embryos on birthweight of newborns. Hum Reprod (Oxford, England) 2010; 25: 605-612.

214 Le Bouc Y, Rossignol S, Azzi S, Steunou V, Netchine I, Gicquel C: Epigenetics, genomic imprinting and assisted reproductive technology. Ann Endocrinol 2010; 71: 237-238.

215 Doherty AS, Mann MR, Tremblay KD, Bartolomei MS, Schultz RM: Differential effects of culture on imprinted $\mathrm{H} 19$ expression in the preimplantation mouse embryo. Biol Reprod 2000; 62: 1526-1535.

216 Chang AS, Moley KH, Wangler M, Feinberg AP, Debaun MR: Association between Beckwith-Wiedemann syndrome and assisted reproductive technology: a case series of 19 patients. Fertil Steril 2005; 83: 349-354.

217 Sutcliffe AG, Peters CJ, Bowdin S et al: Assisted reproductive therapies and imprinting disorders-a preliminary British survey. Hum Reprod (Oxford, England) 2006; 21: 1009-1011.

218 Doornbos ME, Maas SM, McDonnell J, Vermeiden JP, Hennekam RC: Infertility, assisted reproduction technologies and imprinting disturbances: a Dutch study. Hum Reprod (Oxford, England) 2007; 22: 2476-2480.

219 Lidegaard O, Pinborg A, Andersen AN: Imprinting diseases and IVF: Danish National IVF cohort study. Hum Reprod (Oxford, England) 2005; 20: 950-954.

220 Odom LN, Segars J: Imprinting disorders and assisted reproductive technology. Curr Opin Endocrinol Diabetes Obes 2010; 17: 517-522.

221 Khoury MJ, Holtzman NA: On the ability of birth defects monitoring to detect new teratogens. Am J Epidemiol 1987; 126: 136-143.

222 Mittendorf R: Teratogen update: carcinogenesis and teratogenesis associated with exposure to diethylstilbestrol (DES) in utero. Teratology 1995; 51: 435-445.

223 Reefhuis J, Honein MA, Schieve LA, Correa A, Hobbs CA, Rasmussen SA: Assisted reproductive technology and major structural birth defects in the United States. Hum Reprod (Oxford, England) 2009; 24: 360-366.

224 Finnstrom O, Kallen B, Lindam A, Nilsson E, Nygren KG, Olausson PO: Maternal and child outcome after in vitro fertilization-a review of 25 years of population-based data from Sweden. Acta Obstet Gynecol Scand 2011; 90: 494-500.

225 Sunderam S, Kissin DM, Flowers $L$ et al: Assisted reproductive technology surveillance-United States, 2009. MMWR Surveill Summ 2012; 61: 1-23.

226 Ben-David U, Kopper O, Benvenisty N: Expanding the boundaries of embryonic stem cells. Cell Stem Cell 2012; 10: 666-677.

227 Tiscornia G, Vivas EL, Izpisua Belmonte JC: Diseases in a dish: modeling human genetic disorders using induced pluripotent cells. Nat Med 2011; 17: $1570-1576$.

228 Seriola A, Spits C, Simard JP et al: Huntington's and myotonic dystrophy hESCs: down-regulated trinucleotide repeat instability and mismatch repair machinery expression upon differentiation. Hum Mol Genet 2011; 20: 176-185.

229 Liu GH, Ding Z, Izpisua Belmonte JC: iPSC technology to study human aging and aging-related disorders. Curr Opin Cell Biol 2012; 24: 765-774.

230 Spits C, Mateizel I, Geens M et al: Recurrent chromosomal abnormalities in human embryonic stem cells. Nat Biotechnol 2008; 26: 1361-1363.

231 Van Haute L, Spits C, Geens M, Seneca S, Sermon K: Human embryonic stem cells commonly display large mitochondrial DNA deletions. Nat Biotechnol 2013; 31: 20-23.

232 Amps K, Andrews PW, Anyfantis G et al: Screening ethnically diverse human embryonic stem cells identifies a chromosome 20 minimal amplicon conferring growth advantage. Nat Biotechnol 2011; 29: 1132-1144.

233 Zhang Y, Yao L, Yu X, Ou J, Hui N, Liu S: A poor imitation of a natural process: A call to reconsider the iPSC engineering technique. Cell Cycle (Georgetown, TX) 2012; 11 4536-4544.

234 Council of Europe. Background document on preimplantation and prenatal genetic testing 2011; http://www.coe.int/t/dg3/healthbioethic/Source/INF_2010_6_dpidpn _en.pdf. Accessed: July 2013.

235 Mayhew SH, Gerein N, Green A, Cleland J: Improving health systems and enhancing reproductive health: linkages and lessons for action. Health Policy Plan 2004; 19(Suppl 1): i1-i4.

236 Hassan MA, Killick SR: Negative lifestyle is associated with a significant reduction in fecundity. Fertil Steril 2004; 81: 384-392.

237 Ekelin M, Akesson C, Angerud M, Kvist LJ: Swedish high school students' knowledge and attitudes regarding fertility and family building. Reprod Health 2012; 9: 6 .

238 Schmidt L, Sobotka T, Bentzen JG, Nyboe Andersen A: Demographic and medical consequences of the postponement of parenthood. Hum Reprod Update 2012; 18: 29-43.

239 van den Akker OB: Adoption in the age of reproductive technology. J Reprod Infant Psychol 2001; 19: 147-159.

240 European Commission. 25 Recommendations on the ethical, legal and social implications of genetic testing 2004; http://ec.europa.eu/research/conferences/ 2004/genetic/pdf/recommendations_en.pdf. Accessed: July 2013.

241 Connolly MP, Ledger W, Postma MJ: Economics of assisted reproduction: access to fertility treatments and valuing live births in economic terms. Hum Fertil (Cambridge, England) 2010; 13: 13-18.

242 Quigley M: A right to reproduce? Bioethics 2010; 24: 403-411.
243 Chan CC, Ho PC: Infertility, assisted reproduction and rights. Best Pract Res Clin Obstet Gynaecol 2006; 20: 369-380.

244 Birenbaum-Carmeli D, Dirnfeld M: In vitro fertilisation policy in Israel and women's perspectives: the more the better? Reprod Health Matters 2008; 16: 182-191.

245 Grant JHS, Gallo F, Cave J: A Preliminary Assessment of the Demographic and Economic Impact of Assisted Reproductive Technologies. RAND Corporation: Santa Monica, California, 2006

246 Mladovsky P, Sorenson C: Public financing of IVF: a review of policy rationales. Health Care Anal 2010; 18: 113-128.

247 Daniels N: Just Health Care. Studies in Philosophy and Health Policy. Cambridge University Press: Cambridge/New York, 1985

248 Dondorp W, de Wert G, Pennings G et al: Lifestyle-related factors and access to medically assisted reproduction. Hum Reprod (Oxford, England) 2010; 25: $578-583$.

249 United Kingdom Government. Human Fertilisation and Embryology Act 2008; http://www.legislation.gov.uk/ukpga/2008/22/contents. Accessed: July 2013.

250 Pennings G: Measuring the welfare of the child: in search of the appropriate evaluation principle. Hum Reprod (Oxford, England) 1999; 14: 1146-1150.

251 van Rij M, de Die-Smulders C, Bijlsma E et al: Evaluation of exclusion prenatal and exclusion preimplantation genetic diagnosis for Huntington's disease in the Netherlands. Clin Genet 2013; 83: 118-124.

252 De Wert G: Ethics of preimplantation genetic diagnosis: the case of preimplantation genetic diagnosis; In: BCJM Fauser et al: (eds) Molecular Biology in Reproductive Medicine. Parthenon: New York/London, 1999; pp 433-450.

253 De Wert G: Preimplantation genetic testing: normative reflections; In: Harper J (ed) Preimplantation Genetic Diagnosis. Cambridge University Press: Cambridge, 2009; pp 259-273.

254 Tuffs A: Germany allows restricted access to preimplantation genetic testing. BMJ 2011; 343: d4425.

255 Habermas J: The Future of Human Nature. Polity Press: Cambridge, 2003.

256 Dondorp W, De Wert G, Pennings G et al: ESHRE Task Force on ethics and Law 20: sex selection for non-medical reasons. Hum Reprod (Oxford, England) 2013; 28: $1448-1454$.

257 Geraedts JP, De Wert GM: Preimplantation genetic diagnosis. Clin Genet 2009; 76 315-325.

258 Shenfield F: [Preimplantation genetic diagnosis in order to choose a saviour sibling]. Gynecol Obstet Fertil 2005; 33: 833-834.

259 de Wert G: Preimplantation genetic diagnosis: the ethics of intermediate cases. Hum Reprod (Oxford, England) 2005; 20: 3261-3266.

260 Wertz DC, Knoppers BM: Serious genetic disorders: can or should they be defined? Am J Med Genet 2002; 108: 29-35.

261 Bredenoord AL, Pennings G, Smeets HJ, de Wert G: Dealing with uncertainties: ethics of prenatal diagnosis and preimplantation genetic diagnosis to prevent mitochondrial disorders. Hum Reprod Update 2008; 14: 83-94.

262 Poulton J, Kennedy S, Oakeshott P, Wells D: Preventing transmission of maternally inherited mitochondrial DNA diseases. BMJ 2009; 338: b94.

263 Bredenoord AL, Krumeich A, De Vries MC, Dondorp W, De Wert G: Reproductive decision-making in the context of mitochondrial DNA disorders: views and experiences of professionals. Clin Genet 2010; 77: 10-17.

264 Nuffield Council on Bioethics: Novel techniques for the prevention of mitochondrial DNA disorders: an ethical review. Nuffield Council on Bioethics: London, 2012.

265 de Wert G, Dondorp W, Pennings G et al: Intrafamilial medically assisted reproduction. Hum Reprod (Oxford, England) 2011; 26: 504-509.

266 Bredenoord AL, Dondorp W, Pennings G, De Wert G: Ethics of modifying the mitochondrial genome. J Med Ethics 2011; 37: 97-100.

267 Council of Europe. Convention for the protection of Human Rights and Dignity of the Human Being with regard to the Application of Biology and Medicine: Convention on Human Rights and Biomedicine CETS No.: 164 1997; http://conventions.coe.int/ Treaty/Commun/QueVoulezVous.asp?NT=164\&CL=ENG. Accessed: July 2013.

268 The Hinxton Group. International Consortium on Stem Cells, Ethics \& Law: Consensus Statement: Science, Ethics and Policy Challenges of Pluripotent Stem Cell-Derived Gametes 2008; http://www.hinxtongroup.org/Consensus_HG08_ FINAL.pdf. Accessed: July 2013.

269 Omurtag K, Jimenez PT, Ratts V, Odem R, Cooper AR: The ART of social networking: how SART member clinics are connecting with patients online. Fertil Steril 2012 97: 88-94.

270 Lagan BM, Sinclair M, Kernohan WG: What is the impact of the Internet on decisionmaking in pregnancy? A global study. Birth (Berkeley, CA) 2011; 38: 336-345.

271 Morris JK: Is cascade testing a sensible method of population screening? J Med Screen 2004; 11: 57-58.

272 Newson AJ, Humphries SE: Cascade testing in familial hypercholesterolaemia: how should family members be contacted? Eur J Hum Genet 2005; 13: 401-408.

273 Hofman N, Tan HL, Alders M, van Langen IM, Wilde AA: Active cascade screening in primary inherited arrhythmia syndromes: does it lead to prophylactic treatment? J Am Coll Cardiol 2010; 55: 2570-2576.

274 De Wert GM, Dondorp WJ, Knoppers BM: Preconception care and genetic risk: ethical issues. J Commun Genet 2012; 3: 221-228.

275 Bell CJ, Dinwiddie DL, Miller NA et al: Carrier testing for severe childhood recessive diseases by next-generation sequencing. Sci Trans Med 2011; 3: 65ra64.

276 Clarke A, Thirlaway K: Genetic counselling for personalised medicine. Hum Genet 2011 ; 130: 27-31. 
277 Practice Committee of American Society for Reproductive Medicine and Practice Committee of Society for Assisted Reproductive Technology. Recommendations for gamete and embryo donation: a committee opinion. Fertil Steril 2013; 99: 47-62.

278 Daar JF, Brzyski RG: Genetic screening of sperm and oocyte donors: ethical and policy implications. J Am Med Assoc 2009; 302: 1702-1704.

279 Maron BJ, Lesser JR, Schiller NB, Harris KM, Brown C, Rehm HL: Implications of hypertrophic cardiomyopathy transmitted by sperm donation. J Am Med Assoc 2009; 302: 1681-1684.

280 Sims CA, Callum P, Ray M, Iger J, Falk RE: Genetic testing of sperm donors: survey of current practices. Fertil Steril 2010; 94: 126-129.

281 Hens K, Dondorp W, Handyside AH et al: Dynamics and ethics of comprehensive preimplantation genetic testing: a review of the challenges. Hum Reprod Update 2013; 19: 366-375

282 Handyside AH, Xu K: Preimplantation genetic diagnosis comes of age. Semin Reprod Med 2012; 30: 255-258.

283 Sandel M: The Case Against Perfection: Ethics in the Age of Genetic Engineering. Belknap Press: Cambridge, MA, USA, 2007.

284 Savulescu J, Kahane G: The moral obligation to create children with the best chance of the best life. Bioethics 2009; 23: 274-290.

285 German Parliament. Gendiagnostikgesetz vom 31. Juli 2009 (BGBI. I S. 2529 3672). http://www.gesetze-im-internet.de/bundesrecht/gendg/gesamt.pdf. Accessed: July 2013.

286 European Commission Directive 2011/24/EU of the European Parliament and of the Council of 9 March 2011 on the application of patients' rights in cross-border healthcare. http://eur-lex.europa.eu/LexUriServ/LexUriServ.do?uri=OJ: L:2011:088:0045:0065:EN:PDF. Accessed: July 2013.

287 Metzler I: On why states still matter: in vitro fertilzation embryos between laboratories and state authorities in Italy; In: Vermeulen NTS, Webster A (eds) Bio-objects: Life in the 21st Century. Ashgate: United Kingdom, 2012.

288 The Nordic Committee on Bioethics and The Norwegian Biotechnology Advisory Board. Summary of Conference: Prenatal Diagnosis_Individuals and Society 2010; http://ncbio.org/nordisk/arkiv/oslo-summary-final.pdf. Accessed: July 2013.
289 Haddow JEPG: ACCE: a model process for evaluating data on emerging genetic tests; In: Khoury MLJ, Burke W (eds) Human Genome Epidemiology: A Scientific Foundation for Using Genetic Information to Improve Health and Prevent Disease. Oxford University Press, 2003; pp 217-233.

290 Centers for Diseases Control of the United States of America. ACCE Model Process for Evaluating Genetic Testing 2004; http://www.cdc.gov/genomics/gtesting/ACCE/ index.htm. Accessed: July 2013.

291 Greely HT: Get ready for the flood of fetal gene screening. Nature 2011; 469: 289-291.

292 European Court of Human Rights 2012; http://www.echr.coe.int/. Accessed: July 2013.

293 Council of Europe. European Convention of Human Rights 2010; http://www.echr. coe.int/Documents/Convention_ENG.pdf. Accessed: July 2013

294 Van Hoof W, Pennings G: The consequences of S.H. and Others V. Austria for legislation on gamete donation in Europe: an ethical analysis of the European Court of Human Rights judgments. Reprod Biomed Online 2012; 25 : 665-669.

295 European Court of Human Rights. Judgement in the Case of S.H. and Others v. Austria (Application no. 57813/00) 2011; http://hudoc.echr.coe.int/sites/eng/pages/ search.aspx?i=001-107325\#\{\%22itemid\%22:[\%22001-107325\%22]\}. Accessed: July 2013.

296 Mason JK, Laurie GT: The management of infertility and childlessness; In: Mason \& McCall Smith's Law and Medical Ethics, 7th Edn, Oxford University Press: Oxford, UK, 2006; pp 309-318.

(c) (i) (5) $\odot$ This work is licensed under a Creative Commons Attribution-NonCommercial-NoDerivs 3.0 Unported License. To view a copy of this license, visit http://creative commons.org/licenses/by-nc-nd/3.0/ 